\title{
Geographic population genetic structure and diversity of Sophora moorcroftiana based on genotyping-by-sequencing (GBS)
}

\author{
Ying Liu ${ }^{1,2}$, Fei Yi ${ }^{1}$, Guijuan Yang ${ }^{1}$, Yuting Wang ${ }^{3}$, Ciren Pubu ${ }^{3}$, Runhua He ${ }^{4}$, Yao Xiao ${ }^{1}$, Junchen Wang ${ }^{1,2}$, Nan \\ Lu $^{1}$, Junhui Wang ${ }^{1}$, Wenjun Ma ${ }^{\text {corresp. } 1}$ \\ ${ }^{1}$ State Key Laboratory of Tree Genetics and Breeding, Key Laboratory of Tree Breeding and Cultivation of State Forestry Administration, Research \\ Institute of Forestry, Chinese Academy of Forestry, Beijing, China \\ 2 College of Forestry, Northwest A\&F University, Yangling, Shaanxi, China \\ 3 Forest Science Research Institute of Tibet Municipality, Lhasa, Tibet, China \\ 4 College of Forestry, Central South University of Forestry and Technology, Changsha, Hunan, China \\ Corresponding Author: Wenjun Ma \\ Email address: mwjlx.163@163.com
}

Sophora moorcroftiana is a perennial leguminous low shrub endemic to the Yarlung Zangbo River basin in Tibet with irreplaceable economic and ecological value. To determine the drivers of evolution in this species, 225 individuals belonging to 15 populations from different geographic locations were sampled and population genetics was studied using high-throughput genotyping-by-sequencing (GBS). Based on genetic diversity analysis, phylogenetic analysis, principal component analysis, and structure analysis, 15 natural populations could be clustered into five subgroups: subgroup I (Shigatse subgroup) was located in the upper reaches of the Yarlung Zangbo River with a relatively high level of population genetic variation (means for PIC, Shanon and PI were $0.173,0.326$ and 0.0000305 , respectively), and gene flow within the subgroup was also high (mean value for $\mathrm{Nm}$ was 4.67). Subgroup II (including Pop 7 and Pop 8, means for PIC, Shanon and PI were $0.182,0.345$ and 0.0000321 , respectively), located in the middle reaches of the Yarlung Zangbo River had relatively high levels of gene flow with the populations distributed in the upper and lower reaches, The $\mathrm{Nm}$ between subgroup II with subgroup I and III were 3.271 and 2.894, respectively Taking all genetic diversity indices into account, Pop 8 had relatively high genetic diversity. Subgroup III (the remaining mixed subgroup of Lhasa and Shannan) was located in the middle reaches of Yarlung Zangbo River and the means for PIC, Shanon and PI were 0.172, 0.324 and 0.0000303, respectively. Subgroup IV (Nyingchi subgroup), located in the lower reaches of the Yarlung Zangbo River basin, had further genetic distance with the other subgroups and the means for PIC, Shanon and PI were 0.147, 0.277 and 0.0000263 , respectively. Subgroup V (Nyingchi Gongbu Jiangda subgroup), located in the upper reaches of the Niyang River, 
had the lowest level of genetic variation (means for PIC, Shanon and PI were 0.106, 0.198 and 0.0000187 , respectively) and gene flow with other populations (mean value for $\mathrm{Nm}$ was 0.42 ). According to the comprehensive analysis, the $S$. moorcroftiana populations generally expanded from upstream to downstream, and formed a high level of genetic differentiation in the populations in upper and lower reaches. There were high levels of gene exchange between the central populations and upstream and downstream populations, and wind-induced seed dispersal was an important factor in the formation of this gene exchange mode. 


\section{Geographic Population Genetic Structure and}

2 Diversity of Sophora moorcroftiana based on

3 Genotyping-by-Sequencing (GBS)

4

5

Ying Liu ${ }^{1,2}$, Fei Yi ${ }^{1}$, Guijuan Yang ${ }^{1}$, Yuting Wang ${ }^{3}$, Ciren $\mathrm{Pubu}^{3}$, Runhua $\mathrm{He}^{4}$, Yao Xiao ${ }^{1}$, Junchen Wang ${ }^{1,2}$, Nan Lu' ${ }^{1}$, Junhui Wang ${ }^{1}$, Wenjun $\mathrm{Ma}^{1}$

${ }^{1}$ State Key Laboratory of Tree Genetics and Breeding, Key Laboratory of Tree Breeding and Cultivation of State Forestry Administration, Research Institute of Forestry, Chinese Academy of Forestry, Beijing 100091, China

${ }^{2}$ College of Forestry, Northwest A\&F University, Yangling 712100, Shaanxi, China

${ }^{3}$ Forest Science Research Institute of Tibet Municipality, Lhasa 850000, Tibet, China

${ }^{4}$ College of Forestry, Central South University of Forestry and Technology, Changsha 410004, Hunan, China

Corresponding Author:

Wenjun $\mathrm{Ma}^{1}$

No. 1 Xiangshan Road, Haidian District, Chinese Academy of Forestry. Beijing, 100091, China

Email address: mwjlx.163@163.com

\section{Abstract}

Sophora moorcroftiana is a perennial leguminous low shrub endemic to the Yarlung Zangbo River basin in Tibet with irreplaceable economic and ecological value. To determine the drivers of evolution in this species, 225 individuals belonging to 15 populations from different geographic locations were sampled, and population genetics was studied using high-throughput genotyping-by-sequencing (GBS). Based on genetic diversity analysis, phylogenetic analysis, principal component analysis, and structure analysis, 15 natural populations were clustered into the following five subgroups: subgroup I (Shigatse subgroup) was located in the upper reaches of the Yarlung Zangbo River with a relatively high level of population genetic variation (means for PIC, Shannon and PI were 0.173, 0.326 and 0.0000305, respectively), and gene flow within the subgroup was also high (mean value for $\mathrm{Nm}$ was 4.67). Subgroup II (including Pop 7 and Pop 8; means for PIC, Shannon and PI were 0.182, 0.345 and 0.0000321 , respectively), located in the 
33

34

35

36

37

38

39

40

41

42

43

44

45

46

47

48

49

50

51

52

\section{3}

54

55

56

57

58

59

60

61

62

63

64

65

66

67

68

69

70

middle reaches of the Yarlung Zangbo River had relatively high levels of gene flow with the populations distributed in the upper and lower reaches. The $\mathrm{Nm}$ between subgroup II with subgroups I and III was 3.271 and 2.894, respectively. Considering all the genetic diversity indices, Pop 8 had relatively high genetic diversity. Subgroup III (the remaining mixed subgroup of Lhasa and Shannan) was located in the middle reaches of the Yarlung Zangbo River and the means for PIC, Shannon and PI were 0.172, 0.324 and 0.0000303, respectively. Subgroup IV (Nyingchi subgroup), located in the lower reaches of the Yarlung Zangbo River basin, showed a further genetic distance from the other subgroups and the means for PIC, Shannon and PI were $0.147,0.277$ and 0.0000263 , respectively. Subgroup V (Nyingchi Gongbu Jiangda subgroup), located in the upper reaches of the Niyang River, had the lowest level of genetic variation (means for PIC, Shannon and PI were 0.106, 0.198 and 0.0000187, respectively) and gene flow with other populations (mean value for $\mathrm{Nm}$ was 0.42 ). According to the comprehensive analysis, the $S$. moorcroftiana populations generally expanded from upstream to downstream and displayed a high level of genetic differentiation in the populations in the upper and lower reaches. There were high levels of gene exchange between the central populations and upstream and downstream populations, and wind-induced seed dispersal was an important factor in the formation of this gene exchange mode.

Keywords Sophora moorcroftiana, GBS, SNP, population genetics, phylogeography, gene flow

\section{Introduction}

Molecular markers are extremely useful in plant and animal genetics and genomics. Single nucleotide polymorphism (SNP) genetic markers are one of the key tools for population genetics and quantitative genetics. Genotyping-by-sequencing (GBS) is a high-throughput, multiplex and short-read sequencing approach that reduces genome complexity via restriction enzymes and generates high-density genome-wide markers at a low cost per sample by tagging random DNA fragments shared by different samples with unique, short DNA sequences (barcodes) and pooling samples into a single sequencing channel (Elshire et al., 2011). This approach not only greatly reduces the cost of sequencing but also makes it possible to genotype large samples. GBS is of great significance for understanding the genetic background and phylogeny of germplasm resources (Poland et al., 2012; Glaubitz et al., 2014). The short-read sequences obtained by GBS can be assembled by a reference genome or nonreference genome to obtain high-density SNP markers. These SNP markers or developed bin markers can be used for various processes, such as genetic map construction (Ward et al., 2013), genome-wide association studies (GWAS) (Sakiroglu et al., 2017), and genome assembly. At present, GBS technology is an important tool for genotyping and is widely used in genetic linkage mapping, genetic selection (Zhang et al., 2018), genetic diversity studies ( Lu et al., 2013), germplasm identification (Wu et al., 2014), species identification (Pembleton et al., 2016) and other fields. 
The Yarlung Zangbo River basin stretches over large areas of the Lhasa, Shigatse and Shannan regions of Tibet and over small areas within the Ngari, Nagqu and Qamdo regions, including 41 counties (cities). The relief of the basin is high in the west, low in the east, high in the north and south, and low in the central reaches. The Yarlung Zangbo River basin is sensitive to the evolution of the eco-environment, as most of the ground surface of the basin is below the lower one-third of the air convection layer and is therefore vulnerable to global climate change. Due to the monsoons and subtropical westerly jet over the plateau, the river valley exhibits a dry, cold and windy climate (Dong et al., 1997). As the orientation of the river valley is nearly parallel to the wind direction, the mountainous terrain greatly increases the wind velocity. Thus, the Yarlung Zangbo River valley has favorable environmental conditions for the development of aeolian sand landforms, including a sand source, a wind driving force, and deposition fields ( $\mathrm{Li}$ et al., 1999). In total, there were 273,697.54 ha of aeolian sandy land in the Yarlung Zangbo River basin in 2008 (Shen et al., 2012). Desertification in Tibet is an urgent problem that must be addressed (Zou et al., 2002). Sophora moorcroftiana is a vital species for desertification control.

S. moorcroftiana (Benth.) Benth. ex Baker (Fabaceae), a diploid $(2 \mathrm{n}=2 \mathrm{x}=18$; Wang et al., 1995), is acknowledged as a long-lived perennial shrub species endemic to the Qinghai-Tibet Plateau (QTP). This species exists in China Tibet as well as Bhutan, N Burma, and N India (Liu et al., 2006) and is mainly distributed in the middle and upper reaches of the dry valley region of the Yarlung Zangbo River in Tibet with altitudes ranging from 2,800 $\mathrm{m}$ to 4,400 $\mathrm{m}$ ( $\mathrm{Li}$ et al., 2017). It plays an irreplaceable role in Tibet as important forage, and the seeds are used in China as a crude drug (Chang, 1977). Furthermore, the species is currently the preferred droughtresistant afforestation tree species due to its strong adaptability to sand burial in the plateau (Zhao et al., 2007), leading to its irreplaceable role in vegetation reestablishment programs aiming to stabilize shifting sand (Liu et al., 1998). Meanwhile, the species has received much attention due to its medicinal properties (Zhang et al., 2018).

Another Sophora species in the QTP, S. davidii, which is an important leguminous shrub widely distributed in southeastern China (Zhang et al., 2006), is closely related to $S$. moorcroftiana $(W u, 1983)$ and is widely distributed from the southeast of the QTP to central China. Although these two species share many characteristics, such as being diploid $(2 n=18)$, insect-pollinated, and gravity-dispersed via propagules, a hypothesis was proposed in which $S$. moorcroftiana diverged from $S$. davidii and speciated (Shen, 1996). Many studies have found large differences in the phenotypes of $S$. moorcroftiana at different altitudes in the Yarlung Zangbo River basin, but few studies focus on its genetics in different locations. Understanding the genetic evolution of $S$. moorcroftiana has important implications for germplasm conservation and vegetation reconstruction. Even though Liu et al. (2006) has reported the genetic variation in S. moorcroftiana examined using allozyme markers, existing research in this area is still rare. To explore the relationships between the distribution and expansion of S. moorcroftiana and geographical factors, we employed GBS to call SNPs of 15 S. moorcroftiana populations originated from different geographical locations and leveraged them for further analyses. 
The specific goals of this study are (1) to determine the genetic characteristics within and among populations; (2) to examine the effects of altitude and longitude on the population genetic characteristics; and (3) to find historical, life history, and/or environmental factors that might explain the patterns and levels of observed genetic variation.

\section{Materials \& Methods}

\section{Plant material collection}

To determine the correlation between the evolution of $S$. moorcroftiana populations and geographical factors, we utilized the following sampling design: (1) we selected sampling points along a river but separated by a mountain (Pop 8 and Pop 9, Lhasa River Basin) to verify the relationship between the population expansion and water flow; (2) we selected sampling sites from the highest (Pop 3, Shigatse) altitude to the lowest (Pop 14, Nyingchi) altitude and from the lowest longitude (Pop 1, Shigatse) to the maximum longitude (Pop 15, Nyingchi) where $S$. moorcroftiana exists to verify the impacts of altitude and longitude on the population genetic characteristics; and (3) we selected sampling sites on different slopes (e.g., Pop 7 and Pop 8, Pop 9 and Pop 10, and Pop 12 and Pop 13) and in different directions to verify the relationship between the populations and the direction of sand flow caused by the slope and wind (Fig. 1). We obtained a total of 225 samples representing 15 natural populations from 15 locations (15 individuals per location), which were used for the analysis (Table 1), and the populations were numbered according to longitude. In addition, Sophora davidii (Franch.) (individuals 226-229) was used as the outgroup to prevent ascertainment bias. For DNA extraction, young leaf tissue was collected, immediately frozen in liquid nitrogen, and stored at $-80^{\circ} \mathrm{C}$.

\section{DNA extraction and GBS}

The DNA of the young leaves of $S$. moorcroftiana and $S$. davidii individuals was extracted for GBS using a modified cetyltrimethylammonium bromide (CTAB) extraction method (Tel-zur et al., 1999). We employed a two-enzyme (MseI and TaqaI) GBS protocol modified from a previously described protocol (Poland et al., 2012) to generate a library consisting of DNA fragments with a barcode and performed sequencing with an Illumina HiSeq PE 150. The average sequencing depth for each sample was $10 \times$.

\section{SNP data analysis}

Quality control of the FASTQ-format raw data was performed with the FastQC application (Brown et al., 2017) to ensure that there were no hidden problems. Adapter sequences and abnormal nucleotide bases at the 5' terminus were removed from the raw sequencing reads using FastQC 0.6.0. Additionally, the low quality ends of the reads (sequence quality $<Q 20$ ) were trimmed and we removed reads that contained $10 \% \mathrm{Ns}$ (undefined bases) and sequence lengths less than $25 \mathrm{bp}$ after trimming. Then, the bash command cat was used to combine the two sequences generated by paired-end sequencing of each sample into one sequence. Without a 
149

150

151

152

153

154

155

156

157

158

159

160

161

162

163

164

165

166

167

168

169

170

171

172

173

174

175

176

177

178

179

180

181

182

183

184

185

186

187

reference sequence, SNP calling for each sample was performed using the Stacks (Version 2.0 Beta 8, http://catchenlab.life.illinois.edu/stacks/) pipeline to build loci (ustacks), create a catalog of loci (cstacks), match samples back to the catalog (sstacks), transpose the data (tsv2bam), add paired-end reads to the analysis, call genotypes, and perform population genomics analysis (Catchen et al., 2013). The following SNP-filtering parameters were used to construct the phylogenetic tree in VCFtools v4.0 (Danecek et al., 2011, http://vcftools.github.io/): -min DP 5 (minor depth $\geqq 5$ ), -max-missing 0.8 , -maf 0.05 (minor allele frequencies $\geqq 5 \%$ ) and a distance between variants of $300 \mathrm{bp}$. A phylogenetic tree of 229 samples was constructed using the neighbor-joining (NJ) method by Mega7.0 in Linux. The tree file was imported into the Interactive Tree of Life (ITOL) (https://itol.embl.de/itol.cgi) (Letunic et al., 2016), which is an online tool for the display, annotation and management of phylogenetic trees. ADMIXTURE linux-1.3.0 (Alexander et al., 2009) is a software that is commonly used for population structure analysis. Bayesian model-based clustering was used to assign all individuals from all geographic locations to taxa by ADMIXTURE. The number of genetic clusters, $K$, was tested from 2 to 15 , and 14 independent runs were computed for each $K$ value. Principal component analysis (PCA) is a pure mathematics method that can select a small number of important variables from multiple related variables. PCA of SNPs obtained from the 229 samples was performed using GCTA (Yang et al., 2011) (http://cnsgenomics.com/software/gcta/\#PCA) software for the clustering of the main components. The nucleotide diversity (PI, Nei, 1987), Tajima's D (Tajima, 1989), Shannon-Wiener index (Keylock, 2005), polymorphic information content (PIC, Nagy et al., 2012), observed heterozygosity ( $\mathrm{Ho}$ ), and the expected heterozygosity $(\mathrm{He})$ of the $15 \mathrm{~S}$. moorcroftiana populations and the fixation index $\left(F_{\mathrm{ST}}\right)$ among populations were calculated by Stacks. Linear regression analysis of the PIC, Shannon-Wiener index and PI with altitude and longitude was conducted using Excel. By inverting Wright's formula (Wright, 1951), the value of $N m$ can be estimated from $F_{\mathrm{ST}}$, as $N m \approx\left(1-F_{\mathrm{ST}}\right) / 4 F_{\mathrm{ST}}$, where $\mathrm{N}$ is the effective population size of each population and $\mathrm{m}$ is the migration rate between populations. This method is effective for estimating gene flow indirectly.

\section{Results}

\section{Phylogenetic analysis}

In the phylogenetic analysis of the 229 samples (Fig. 2), S. davidii individuals 226-229 (outgroup) were the farthest from the other individuals and separated from other individuals at the base of the tree. Within the S. moorcroftiana populations, Pop 13 (Nyingchi, Gongbu Jiangda county), which contained individuals 181-195, was the first population that separated from the other populations. Pop 12 (individuals 91-105), Pop 14 (individuals 121-135) and Pop 15 (individuals 31-45) from Nyingchi in the Yarlung Zangbo River basin were relatively close and separated from the other populations. Pop 11 (individuals 136-150) and Pop 10 (individuals 151165) clustered together and were relatively far from the other populations. Compared to Pop 8 (individuals 1-15) and Pop 7 (individuals 16-30), Pop 9 (individuals 166-180) in the upper 
188

189

190

191

192

193

194

195

196

197

198

199

200

201

202

203

204

205

206

207

208

209

210

211

212

213

214

215

216

217

218

219

220

221

222

223

224

225

226

227

reaches of the same river basin (Lhasa River) was far away. Among the Shigatse populations, Pop 6 (individuals 106-120) separated from the other populations first (including Pop 5, Pop 4, Pop 3, Pop 1, and Pop 2) and then Pop 5 (individuals 196-210) separated. Meanwhile, Pop 1 was close to Pop 2 and Pop 3 was close to Pop 4. Overall, the populations located in Nyingchi separated first from the populations in other areas, followed by the Shannan populations, Lhasa populations, and finally the Shigatse populations, and there is east-west differentiation.

\section{Population structure analysis}

Estimated ancestries, derived from multilocus genotype data, can be used to perform statistical correction for population stratification (Alexander et al., 2009). We used ADMIXTURE, which adopts the likelihood model embedded in STRUCTURE and runs considerably faster than other tools to estimate ancestry, to identify possible subgroups. When $K$ $=5,6,7$ and 8 , the cross validation errors (CV errors) were relatively low, with $K=7$ minimizing the $\mathrm{CV}$ error (Fig. 3). Clustering information for the $225 \mathrm{~S}$. moorcroftiana individuals when $K=2$ to 9 is shown in Fig. 3B. Moving from $K=2$ to 9 , the large sample from the upper and middle reaches of the Yarlung Zangbo River was first distinguished from the lower and middle reaches, after which the samples from the middle reaches (Shannan, Lhasa) were revealed as distinct. When all the samples were clustered into four taxa, the genetic information of Pop 1, Pop 2, Pop 3, Pop 4, Pop 5 and Pop 6 from the upper reaches of the Yarlung Zangbo River were derived from an ancestor. Pop 9, Pop 10, and Pop 11 were derived from another ancestor, while approximately half of the genetic information for Pop 7 and Pop 8 came from the ancestor of Pop 1-6 and the remaining half came from the ancestor of Pop 9-11. Pop 14 and Pop 15 were derived from an ancestor and approximately $70 \%$ of the information for Pop 12 was from the ancestor of Pop 14, Pop 15. Pop 13 was derived from a single ancestor. When $K=5$, Pop 9 was divided into a different taxon with Pop 10 and Pop 11, and the genetic information for Pop 7 and Pop 8 was still derived from two ancestors. However, the genes were more clearly identified as being from Pop 9. When $K=6$, Pop 7 and Pop 8 were divided into different a taxon with Pop 9. A portion of the genetic information for Pop 12 was from the ancestor of Pop 10 and Pop 11 and the ancestor of Pop 13, which indicates that genetic information can be extended over a certain distance. When $K=7$, Pop 12 was divided into different taxa with Pop 14 and Pop 15, and Pop 14 contained some genetic information from Pop 12.

\section{Principal component analysis}

To supplement the structural analysis results, we used GCTA for PCA. The PCA of SNPs clearly distinguished five major subgroups among the 225 S. moorcroftiana individuals (Fig. 4AC), with the outgroup containing individuals 226-229 excluded. This result confirmed the population structure analysis results when $K=6$, but the only difference is that Pop 9, Pop 10 and Pop 11 were clustered into the same subgroup by PCA. Subgroup I was in the high-altitude and westernmost region of the sampling area, which contained Pop 1, Pop 2, Pop 3, Pop 4, Pop 5, and Pop 6 from Shigatse (Fig. 4D). Subgroup II contained Pop 7 from Shannan and Pop 8 from 
228 Lhasa. Pop 7 was from the confluence of the Lhasa River and the Yarlung Zangbo River and Pop

229

230

231

232

233

234

235

236

237

238

239

240

241

242

243

244

245

246

247

248

249

250

251

252

253

254

255

256

257

258

259

260

261

262

263

264

265

266

267

268

8 belonged to the Lhasa River Basin in detail. Subgroup III was in the middle of the sampling area (Lhasa and Shannan) and contained Pop 9, Pop 10, and Pop 11. Specifically, Pop 9

belonged to the Lhasa River Basin, Pop 10 was from the confluence of the Yalong River and the Yarlung Zangbo River, and Pop 11 belonged to the Yalong River basin. Subgroup IV was in the lowest and easternmost region of the sampling area (Nyingchi, Yarlung Zangbo River basin) and contained Pop 12, Pop 14, and Pop 15. Among these populations, Pop 15 was from the lower reaches of the Niyang River. Subgroup V was located at high altitudes in the eastern sampling area (Nyingchi, Gongbu Jiangda county) and only contained only Pop 13, which was from the upper reaches of the Niyang River. The analyses showed that Pop 13 was obviously separated and differentiated from the other populations. The clustering of populations by PCA roughly conformed to the geographic distribution of the populations.

\section{Population genetic diversity}

Relatively low levels of genetic diversity were found in the S. moorcroftiana populations (Table 2). The PIC is an indicator of the level of polymorphism. The PIC was between 0 and 1 among the 15 populations, with low polymorphism (PIC $<0.25$ ) among populations. The PIC ranged from 0.106 (Pop 13) to 0.183 (Pop 8), with an average of 0.164. The Shannon-Weiner index incorporates the following two factors: species richness and the equitability or evenness of individual distributions. Among all the populations, the index ranged from 0.198 (Pop 13) to 0.346 (Pop 8). PI is a concept used in molecular genetics to measure the degree of polymorphism within a population. The PI ranged from 0.00001873 (Pop 13) to 0.00003233 (Pop 8), with an average of 0.00002904 . The PIC, Shannon, and PI levels of the 15 populations decreased with increasing longitude (Fig. 5A-C) and increased with increasing altitude (Fig. 5D). Although these indices were negatively correlated with longitude overall, populations at an intermediate longitude, especially Pop 7 and Pop 8, had the highest PIC, Shannon, and PI levels. The longitude of Pop 13 was not the highest, but the PIC, Shannon, and PI levels were the lowest. Tajima's D is a statistical test that is mainly used to distinguish whether a DNA sequence has undergone random or nonrandom evolution, and whether or not it underwent directional selection. $\mathrm{T}=0$ indicates that no selection occurred. Tajima's $\mathrm{D}$ was greater than 0 for all the populations, ranging from 0.712 (Pop 10) to 1.296 (Pop 13). The observed heterozygosity ( $\mathrm{Ho}$ ) ranged from 0.2701 (Pop 11) to 0.3249 (Pop 8) and the expected heterozygosity (He) ranged from 0.2956 (Pop 7) to 0.3382 (Pop 14).

Taking all indicators into account, Pop 8 has relatively high genetic diversity.

\section{Population genetic differentiation}

$F_{\mathrm{ST}}$ is a measure of genetic differentiation among populations, and studying the genetic structure of a population is essential to understanding its evolutionary properties (Whitlock and Mccauley, 1999). Wright (Wright, 1965) suggested that an $F_{\mathrm{ST}}$ ranging from 0 to 0.05 indicates very little genetic differentiation between populations and is thus not worth considering; $F_{\mathrm{ST}}$ ranging from 0.05 to 0.15 indicates moderate genetic differentiation between populations; $F_{\mathrm{ST}}$

Peer) reviewing PDF | (2019:04:37034:3:0:NEW 22 May 2020) 
269

270

271

272

273

274

275

276

277

278

279

280

281

282

283

284

285

286

287

288

289

290

291

292

293

294

295

296

297

298

299

300

301

302

303

304

305

306

307

ranging from 0.15 to 0.25 indicates large genetic differentiation between populations; and $F_{\mathrm{ST}}$ greater than 0.25 indicates strong genetic differentiation between populations. As shown in Table 3 , the $F_{\mathrm{ST}}$ between pairs of the 15 populations ranged from 0.021 (Pop 1 with Pop 2) to 0.458 (Pop 15 with Pop 13), with an average of 0.222 , which indicated large genetic differentiation among $S$. moorcroftiana populations. Within the Shigatse populations, Pop 1 had very little genetic differentiation from Pop 2, Pop 5, Pop 3 and Pop 4; Pop 2 had very little genetic differentiation from Pop 5; and Pop 5 was close to Pop 6. Overall, the genetic relationship of the populations in Shigatse was close to each other, and the genetic variation occurred within populations rather than among populations. The degree of genetic differentiation among the populations that were distributed close to one another, such as Pop 7 with Pop 8 and Pop 10 with Pop 11, was low. Pop 7 and Pop 8 generally exhibited a moderate level of genetic differentiation with the populations from Shigatse, including Pop 9, Pop 10, and Pop 11. There was a large genetic difference between Pop 13 and all other populations. This result is complementary to the results of the previous analysis.

\section{Gene flow among populations}

Mutation, genetic drift due to a finite population size, and natural selection favoring adaptations to local environmental conditions will all lead to the genetic differentiation of local populations, and the movement of gametes, individuals, and even entire populationscollectively called gene flow-will oppose that differentiation (Slatkin, 1987). Slatkin indicated that gene flow may either constrain evolution by preventing adaptation to local conditions or promote evolution by spreading new genes and combinations of genes throughout a species' range. One reason for estimating $\mathrm{Nm}$ is that this combination of parameters indicates the relative strengths of gene flow and genetic drift. Genetic drift will result in substantial local differentiation if $N m<1$ but not if $N m>1$ (Wright, 1951). From the $F_{\mathrm{ST}}$, we obtained the gene flow among the 15 populations (Table 4). The higher the gene flow, the lower the degree of genetic differentiation between populations. The gene flow among the Shigatse populations was generally at a high level (mean value for $\mathrm{Nm}$ is 4.668). All the $\mathrm{Nm}$ values among the 6 populations in Shigatse are greater than 1, especially between Pop 1 and Pop 2, where $\mathrm{Nm}$ peaked 11.601. In addition, gene flow exhibited higher levels among the populations distributed close to each other, such as Pop 7 with Pop $8(\mathrm{Nm}=4.750)$ and Pop 10 with Pop $11(\mathrm{Nm}=4.826)$. Pop 7 and Pop 8 (subgroup II) were geographically distributed between the Shigatse subgroup (subgroup I) and the Lhasa-Shannan mixed subgroup (including Pop 9, Pop 10, and Pop 11 in subgroup III), and there were extensive genetic exchanges between Pop 7, Pop 8 and the two subgroups $(N m>1)$. The Nyingchi subgroup (including Pop 12, Pop 14, and Pop 15 in subgroup IV) and the Nyingchi Gongbu Jiangda subgroup (Pop 13 in subgroup V) had low levels of gene flow with the other populations.

Analysis of genetic diversity and $\mathbf{N m}$ for the four main subgroups

Peer] reviewing PDF | (2019:04:37034:3:0:NEW 22 May 2020) 
308

309

310

311

312

313

314

315

316

317

318

319

320

321

322

323

324

325

326

327

328

329

330

331

332

333

334

335

336

337

338

339

340

341

342

343

344

345

346

According to the comprehensive results of the phylogenetic analysis, population structure analysis and PCA analysis, 15 natural populations could be clustered into five subgroups. In order to increase the sample size and verify the analysis results, we removed subgroup V (Pop 13), which has large genetic differences with all the other populations and analyzed the genetic diversity and $\mathrm{Nm}$ of the following four main subgroups: subgroup I) Pop 1-6, subgroup II) Pop 7 and 8, subgroup III) Pop 9-11, and subgroup IV) Pop 12, 14 and 15. Among all the subgroups, subgroup II had higher genetic diversity (Table 5) and had high levels of gene flow with subgroup I $(\mathrm{Nm}=3.271)$ and subgroup III $(\mathrm{Nm}=2.894)$ (Table 6). Subgroup IV showed large genetic differentiation with the other subgroups $(\mathrm{Nm}<1)$, especially with subgroup I and subgroup II. These results are consistent with our previous analysis.

\section{Discussion}

A study on the arenaceous adaptability of $S$. moorcroftiana (Zhao, 1998) revealed that its optimal habitats were terraces covered with sand, semi-motive dunes and the initial stages of fixed sand dunes. This species first invaded and became established in motive dunes by seed reproduction, then became abundant by establishing roots and finally declined owing to interspecific competition. A study on the soil seed bank of S. moorcroftiana (Liu et al., 2002) showed that $70 \%$ of all seeds were distributed on the surface. Seed dispersal was driven by wind, gravity (slope) and water flow, and the dispersal by water flow was closely related to the landforms and the carrying capacity of flowing water. Seeds dispersed by gravity or wind might have been carried away again by water. The regions alongside the Yarlung Zangbo River are covered with mobile dunes, and the degree of desertification in the Yarlung Zangbo River basin is as follows: Shigatse $>$ Shannan $>$ Lhasa $>$ Nyingchi (Xu et al., 2006). In this study, there were high levels of gene flow between populations in Shigatse, which inhibited the genetic differentiation between these populations. Most individuals of $S$. moorcroftiana grow in desertified areas (Zou et al., 2002), and the population density of S. moorcroftiana increased with increasing altitude (Zhao et al., 2007). Therefore, large seed banks are driven by ubiquitous quicksand, which may lead to this phenomenon. The middle reaches of the Yarlung Zangbo River form the center of social and economic development in Tibet and are severely affected by aeolian sands. Pop 7 and Pop 8 in the Lhasa River Basin, located between subgroup I and subgroup III, had higher levels of genetic variation among all populations and had a close genetic relationship between the two subgroups. This expansion direction is contrary to the direction of seed dispersal by water and gravity. A study of aeolian sandy land in the areas around the Lhasa Airport (Li et al., 2010) revealed the trends of wind direction changes in the areas around the Lhasa Airport from 1980-2006 (Fig. 6), showing that west wind (W), east wind (E) and eastnorth $22.5^{\circ}$ wind (ENE) were frequent around Lhasa Airport. This pattern may explain why the genetic information of subgroup I and III was shared with subgroup II and why Pop 5 and Pop 6, at higher altitudes, shared genetic information with subgroup III. The research on genetic diversity of 10 populations of $S$. moorcroftiana near the Yarlung Zangbo River assessed by 
347 allozymes (Zhao et al., 2003) revealed that the population in the middle area (eastern Shigatse 348 and western Shannan) harbored the majority of alleles and had high levels of genetic diversity, 349 which is roughly consistent with our results. In the lower reaches of the Yarlung Zangbo River,

350

351

352

353

354

355

356

357

358

359

360

361

362

363

364

365

366

367

368

369

370

371

372

373

374

375

376

377

378

379

380

381

382

383

384

385

386

Nyingchi has better climate and soil conditions and is rich in species and vegetation resources. $S$. moorcroftiana, which thrives on moving dunes, followed by semifixed dunes, had a declining trend after the sand was fixed (because other species colonized the fixed sand). In addition, there is a negative effect of human pressure and habitat fragmentation. These factors may have resulted in lower population density in Nyingchi and lower gene flow with the populations in other areas. We found significant differences in the flowering period between different regions, which might also have some effect on the gene exchange between different populations. Pop 13 from Gongbu Jiangda county in Nyingchi is located on the eastern slope of Mount Mira in the upper reaches of the Niyang River, which has a temperate and moist climate and high vegetation coverage and species diversity. The environment hinders the spread of seeds and thus causes far genetic distances between Pop 13 and the other populations, except for Pop 12, which shared little genetic information with Pop 13 (potentially due to gravity). In the same basin as Pop 13, Pop 15 is located in the downstream of the Niyang River and is distantly genetically related to upstream Pop 13. The genetic distance between Pop 15 and Pop 13 was greater than the average distance between Pop 13 and the other populations. This finding also indirectly proved the suggested limitations of seed dispersal by water (Liu et al., 2002). Pop 9 is located in the upstream of the Lhasa River on the western slope of Mount Mira. There are clear differences in habitats between the western and eastern slopes of Mount Mira. The western slope has a cold and dry climate, and desertification is severe there. Pop 9 demonstrated extensive gene flow with the populations in adjacent regions, such as Pop 8, Pop 7, and Pop 10. These showed the importance of seed dispersal by gravity, sand and wind.

To explain these results obtained from the GBS SNP dataset, we considered the biotope and overall geographical environment and formulated 3 points on how S. moorcroftiana evolved. (1) S. moorcroftiana originated in high-altitude areas in the west and expanded to lower altitudes in the east via seed dispersal by gravity, wind, sand drifts and water flow. (2) Due to the effects of wind direction, the greatest number of seeds was dispersed into the central region mainly from the east, west, east-northeast and west-southwest, which was one of the greatest factors leading to the high genetic variation in Pop 7 and Pop 8, which are located in the central region. (3) The geographical environment, including the vegetation coverage and the degree of desertification degree, had a strong influence on the expansion of S. moorcroftiana. Pressure from humans may also have a great impact on the genetic characteristics of $S$. moorcroftiana.

Avise (Avise and Hamrick, 1996) pointed out a lack of concern for the genetic diversity of endemic species, and in recent years, the role of population genetics in plant conservation biology has received much attention (Liu et al., 2006; Shao et al., 2009; Rayamajhi et al., 2018). Research on S. moorcroftiana has focused on its medicinal value (Su et al., 2017), alkaloid production (Ma et al., 2018), forage value, drought resistance (Li et al., 2015) and desertification control value (Zhao et al., 1998; 2007).However, there have been few studies on $S$.

Peer) reviewing PDF | (2019:04:37034:3:0:NEW 22 May 2020) 
387

388

389

390

391

392

393

394

395

396

397

398

399

400

401

402

403

404

405

406

407

408

409

410

411

412

413

414

415

416

417

418

419

420

421

422

423

424

425

426

moorcroftiana population genetics. The Tibetan flora is characterized as a young flora with high endemicity ( $W u, 1987)$. A hypothesis was proposed in which $S$. moorcroftiana diverged from $S$. davidii and speciated (Wei-Shou, 1996). Wu hypothesized that the Tibetan flora originated mostly from the paleotropical Tertiary flora in the Hengduan Mountains by adapting to the cold and arid environments associated with the strong uplift of the QTP ( $W u, 1987)$. The results of a study (Cheng et al., 2017) using the cpDNA and ITS of S. moorcroftiana and S. davidii to explore the relationship between the two species support these two hypotheses. This study of genetic diversity indicated that both total genetic diversity and within-population diversity in $S$. moorcroftiana are low, and suggested that $S$. moorcroftiana might have undergone serious bottleneck(s) and genetic drift, which might have been caused by the uplift of the QTP. In our study, the genetic diversity of $S$. moorcroftiana was also generally at a low level, and the relatively high level of genetic variation in the high-altitude areas, such as in all the Shigatse populations, may have resulted from $S$. moorcroftiana adapting to harsh environments over a long period of time.

During the field investigation, we found abundant $S$. moorcroftiana seeds in the sand, and $S$. moorcroftiana has the reproductive characteristic of first invading and becoming established by seed reproduction and then becoming abundant via root turions. Seed banks have a direct effect on population dynamics (Harper, 1977), and $70 \%$ of the $S$. moorcroftiana seed bank in the middle reach of the Yarlung Zangbo River is distributed on the soil surface without litter (Reichman, 1984). The relatively closed habitat has a dense seed bank, showing a high seed yield of S. moorcroftiana seeds in the Yarlung Zangbo River (Liu et al., 2002). The seeds are dispersed by wind, gravity and water flow (Fei and Ling, 1995). The Yarlung Zangbo River originates in the southwestern part of Tibet and is located in the middle of the Himalayas. Due to the plateau's monsoons and subtropical westerly jet, the river valley exhibits a dry, cold and windy climate (Dong et al., 1997). The altitude gradually decreases from the northwest to the southeast, and the orientation of the river valley is nearly parallel to the wind direction. In the winter and spring, the westerly jets are faster (maximum instantaneous wind speed: $35.2 \mathrm{~m} / \mathrm{s}$ ) and more frequent (Dong et al., 1999). These geographic and climatic conditions, such as wind direction, slope caused by the terrain, and flow direction, result in a dynamic environment and may lead to the expansion of $S$. moorcroftiana from high-altitude areas in the west to loweraltitude areas in the east. This expansion is consistent with the possible propagation direction of S. moorcroftiana proposed by Liu (Liu et al., 2006), but the propagation mode was slightly different. Sand activity is the dominant factor affecting vegetation that grows in sand. In particular, the vegetation on semifixed and semimovable sand dunes is most seriously affected, and the species and coverage of vegetation can reflect the stability of sand sources. Vegetation succession proceeds based on sand activity (Chang et al., 2006), and strong winds are a major force affecting sand drift. When winds are strong, the movement of the sand dunes is very rapid (Liu et al., 2001). The movement of seeds caused by sand drift and wind may have led to the high gene exchange flow of subgroup II with subgroup I and subgroup III, which are located in the central region. The resources with a high level of genetic diversity should be specifically 
427 protected and sustainably exploited to enable adaptation to and improvement of extreme 428 environments. The location and environment of Gongbu Jiangda county may have caused the $S$. 429 moorcroftiana individuals in this area to be relatively isolated, leading to a low level of gene 430 flow and high levels of differentiation with other populations. Owing to the abundant rain and

431

432

433

434

435

436

437

438

439

440

441

442

443

444

445

446

447

448

449

450

451

452

453

454

455

456

457

458

459

460

461

462

463

464

465 suitable temperature in Nyingchi, there is a high level of species diversity and a high ratio of vegetation coverage in this area. As a result of the low interspecific competitiveness of $S$. moorcroftiana, it is not the dominant species in Nyingchi. A lower population density and gene flow and human impacts may have led to the lower genetic diversity in Nyingchi. A low population genetic diversity is associated with a low ability to withstand threats (Spielman et al., 2004). Thus, the protection of such populations should be strengthened.

The genetic characteristics and structure of $S$. moorcroftiana are related not only to climate and the geographical environment but also to insect-mediated pollen flow. Pollinator activity as well as dye or pollen dispersal are positively affected by plant population size, density or both (Rossum et al., 2010; Nattero et al., 2011), and most pollen is dispersed over short distances to the first few flowers visited and only occasionally over long ranges (leptokurtic distribution, Thomson and Plowright, 1980; Holmquist et al., 2012). The habitat fragmentation caused by human activities such as overexploitation, grazing, cultivation and road construction also affects the genetic traits of $S$. moorcroftiana. Llorens (2018) indicated that anthropogenic fragmentation may not alter pre-existing patterns of genetic diversity and differentiation in perennial shrubs. Therefore, the main factors affecting the evolutionary history and genetic relationship of $S$. moorcroftiana are climate and the geographical environment. S. moorcroftiana is of great significance to Tibet and other desertified areas, and artificial planting and protection of this species should thus be promoted.

\section{Conclusions}

Through previous studies, we knew that $S$. moorcroftiana diverged from $S$. davidii and speciated in the uplift of the QTP. The driving forces of $S$. moorcroftiana seed dispersal were wind, gravity (slope) and water flow. Furthermore, the unique geographical environment of the QTP caused S. moorcroftiana to expand from the western high-altitude to the eastern lowaltitude areas and from the south and north areas to the Yarlung Zangbo River bank. Our research found that there was a high-level of east-west differentiation in S. moorcroftiana populations in the Yarlung Zangbo River basin due to the different geographical environment. The aeolian desertification of the Yarlung Zangbo River Basin is severe, and seed dispersal driven by wind and sand flow is one of the main factors for the large gene flow between the central groups and eastern and western groups. Thus, seed dispersal caused by gravity, wind, sand flow and geographical distance are the main driving forces contributing to the diffusion pattern of $S$. moorcroftiana populations. Although $S$. moorcroftiana seeds expansion can be driven by water flow, water flow is limited because it is closely related to the landforms and the carrying capacity of flowing water. The barriers between mountains and the competition between 
466 S. moorcroftiana and other species are disadvantages for the expansion of S. moorcroftiana. 467 Considering that $S$. moorcroftiana is of great value in controlling aeolian desertification in Tibet 468 (especially for motive dune and semi-motive dune lands), we should spare no effort to protect 469 and utilize genetic diversity and germplasm resources.

470

471

472

473

474

475

476

477

478

479

480

481

482

483

484

485

486

487

488

489

490

491

492

493

494

495

496

497

498

499

500

501

502

\section{Acknowledgements}

This research was funded by Forestry Industry Research Special Funds for Public Welfare Projects (No. 201504109). We are grateful to Minghao Zhang for his guidance on software usage and data analysis.

\section{References}

Alexander D H, Novembre J, Lange K. 2009. Fast model-based estimation of ancestry in unrelated individuals. Genome Research 19(9):1655-1664 DOI 10.1101/gr.094052.109

Avise J C, Hamrick J L. 1996. Conservation genetics: case histories from nature /. Journal of Applied Ecology 78(4) DOI 10.2307/2265881

Berg E E, Hamrick J L. 1997. Quantification of genetic diversity at allozyme loci. Canadian Journal of Forest Research 27(3):415-424 DOI 10.1139/x96-195

Brown J, Pirrung M, Mccue L A. 2017. Fqc dashboard: integrates fastqc results into a web-based, interactive, and extensible fastq quality control tool. Bioinformatics. DOI 10.1093/bioinformatics/btx373

Catchen J, Hohenlohe, PA, Bassham S, Amores A, Cresko W A. 2013. Stacks: an analysis tool set for population genomics. Molecular Ecology 22(11):3124-3140 DOI $10.1111 / \mathrm{mec} .12354$

Chang S U. 1977. Dictionary of Chinese crude drugs. New Medical College Shanghai Scientific Technological Publishers, Shanghai.

Chang C-P, Zou X-Y, Zhang C-L, Huang Y-M. 2006. The characteristics and distribution of the source area of aeolian sand in the valley of Lhasa river's lower reaches, Tibet, China. Journal of Mountain Science 24(4):3082-3085 DOI 10.1109/IGARSS.2006.791

Cheng S, Qiong L, Lu F, Yonezawa T, Yin G-Q, Song Z-P, Wang Y-G,Yang J, Zhang W-J. 2017. Phylogeography of sophora moorcroftiana supports wu's hypothesis on the origin of tibetan alpine flora. Journal of Heredity DOI 10.1093/jhered/esx028

Danecek P, Auton A, Abecasis G, Albers C A, Banks E, Depristo M A. 2011. The variant call format and vcftools. Bioinformatics 27(15):2156-2158 DOI 10.1109/10.1093/bioinformatics/btr330

Dong G, Chen H, Wang G, Li X, Shao Y, Jin J. 1997. The evolution of deserts with climatic changes in china since 150 ka b.p. Science in China 40(4):370-382 DOI 10.1007/BF02877568 
503

504

505

506

507

508

509

510

511

512

513

514

515

516

517

518

519

520

521

522

523

524

525

526

527

528

529

530

531

532

533

534

535

536

537

538

539

540

541

Dong Y, Li S, Dong G. 1999. Present status and cause of land desertification in the yarlung zangbo river basin. Chinese Geographical Science 9(3):228-235 DOI 10.1007/s11769999-0048-6

Dong Y-X, Li S. 1999. Tentative study on the status and the causes of desertification in yarlung zangbo river basin. Scientia Geographica Sinica 19(1):35-41.

Elshire R J, Glaubitz J C, Sun Q, Poland J A, Kawamoto K, Buckler E S. 2011. A robust, simple genotyping-by-sequencing (gbs) approach for high diversity species. Plos One 6(5): e19379 DOI 10.1371/journal.pone.0019379

Fei Y Y, Ling Z. 1995. Analysis on the mechanism of seed dispersal of puccinellia chinampoensis on alkalized meadow in songnen plain of china. Acta Botanica Sinica.

Glaubitz J C, Casstevens T M, Lu F, Harriman J, Elshire R J, Sun Q. 2014. Tassel-gbs: a high capacity genotyping by sequencing analysis pipeline. Plos One 9(2): e90346. DOI 10.1371/journal.pone.0090346

Harper J L. 1977. The population Biology of Plants. Academic Press, London, UK. Holmquist K G, Mitchell R J, Karron J D. 2012. Influence of pollinator grooming on pollen-mediated gene dispersal in mimulus ringens (phrymaceae). Plant Species Biology 27(1):77-85 DOI 10.1111/j.1442-1984.2011.00329.x

Keylock CJ. 2005. Simpson diversity and the shannon-wiener index as special cases of a generalized entropy. Oikos 109(1):203-207 DOI 10.2307/3548628

Letunic I, Bork P. 2016. Interactive tree of life (itol) v3: an online tool for the display and annotation of phylogenetic and other trees. Nucleic Acids Research 44(Web Server issue): W242-W245 DOI 10.1093/nar/gkw290

Li H, Shen W, Zou C, Sun M, She G. 2010. Spatial distribution and evolution of aeolian sandy land in the areas around Lhasa Airport (Tibet,China) since 1990. Acta Ecologica Sinica 21:5716-5727

Li H E, Yao W J, Fu Y R, Li S K, Guo Q Q, Fu B Y. 2015. De novo assembly and discovery of genes that are involved in drought tolerance in Tibetan Sophora moorcroftiana. Plos One 10(1): e111054- DOI 10.1371/journal.pone.0111054

Li H, Zhang Y, Guo Q, Yao W. 2017. Molecular characterisation of adrebgene from sophora moorcroftiana, an endemic species of plateau. Protoplasma 254(4):1735-1741 DOI 10.1007/s00709-016-1065-9

Li S, Dong G-R, Shen J-Y, Yang P, Liu X-W, Wang Y. 1999. Formation mechanism and development pattern of aeolian sand landform in yarlung zangbo river valley (sci). Science in China Ser D 42(3):272-284 DOI 10.1007/BF02878964

Liu Z, Zhang J, Cheng H, Wei X. 1998. Study on comprehensive rehabilitation of desertified land in the middle Basins of Yarlung Zangbo, Lhasa and Nianchu rivers in Tibet. China Environmental Sciences Press, China.

Liu $Z$ and Zhao W. 2001. Shifting sand control in central Tibet. Ambio 30:376-380 DOI 10.1579/0044-7447-30.6.376 
542

543

544

545

546

547

548

549

550

551

552

553

554

555

556

557

558

559

560

561

562

563

564

565

566

567

568

569

570

571

572

573

574

575

576

577

578

579

580
Liu Z, Zhao W, Li Z. 2002. Characteristics of the seed bank of sophora moorcroftiana population in the middle reach of yarlung zangbo river, tibet. Acta Ecologica Sinica.

Liu Z M, Zhao A M, Kang X Y, Zhou S L, J López-Pujol. 2006. Genetic diversity, population structure, and conservation of sophora moorcroftiana (fabaceae), a shrub endemic to the tibetan plateau. Plant Biology 8(1):81-92 DOI 10.1055/s-2005-872889

Llorens T M, Ayre D J, Whelan R J. 2018. Anthropogenic fragmentation may not alter pre-existing patterns of genetic diversity and differentiation in perennial shrubs. Molecular Ecology 27(7): e021314 DOI 10.1111/mec.14552

Lu F, Lipka A E, Glaubitz J, Elshire R, Cherney J H, Casler M D, Buckler E S, Costich D E. 2013. Switchgrass genomic diversity, ploidy, and evolution: novel insights from a network-based snp discovery protocol. Plos Genetics 9(1): e1003215 DOI 10.1371/journal.pgen.1003215

Ma X-B, Lin H-L, Zhang J-Y, She Y-X, Zhou X-Z, Li X-Z, Cui Y, Wang J, Rabah T, Shao Y. 2018. Extraction and identification of matrine-type alkaloids from sophora moorcroftiana using double-templated molecularly imprinted polymers with hplcms/ms. Journal of Separation Science DOI 10.1002/jssc.201701133

Nagy S, Poczai P, Cernák I, Gorji A M, Hegedüs G, Taller J. 2012. Piccalc: an online program to calculate polymorphic information content for molecular genetic studies. Biochemical Genetics 50(9-10):670-672 DOI 10.1007/s10528-012-9509-1

Nattero J, Malerba R, Medel R, Cocucci A. 2011. Factors affecting pollinator movement and plant fitness in a specialized pollination system. Plant Systematics \& Evolution 296(1-2):77-85 DOI 10.1007/s00606-011-0477-4

Nei M. 1987. Molecular Evolutionary Genetics. Columbia University Press, NY.

Pembleton L W, Drayton M C, Bain M, Baillie R C, Inch C, Spangenberg G C, Wang J-P, Forster J, Cogan N O L. 2016. Targeted genotyping-by-sequencing permits costeffective identification and discrimination of pasture grass species and cultivars. Theoretical \& Applied Genetics 129(5):1-15 DOI 10.1007/s00122-016-2678-2

Poland J, Endelman J, Dawson J, Rutkoski J, Wu S, Manes Y, Dreisigacker S, Crossa J, Sánchez-Villeda H, Sorrells, M, Jannink J L. Genomic selection in wheat breeding using genotyping-by-sequencing. The Plant Genome Journal 5(3):103-113 DOI 10.3835/plantgenome2012.06.0006

Poland $J$ A and Rife T W. 2012. Genotyping-by-sequencing for plant breeding and genetics. The Plant Genome Journal 5(3):92 DOI 10.3835/plantgenome2012.05.0005

Poland J A, Brown P J, Sorrells M E, Jannink J L. 2012. Development of high-density genetic maps for barley and wheat using a novel two-enzyme genotyping-bysequencing approach. Plos One 7(2): e32253 DOI 10.1371/journal.pone.0032253

Rayamajhi $\mathbf{N}$ and Sharma J. 2018. Genetic diversity and structure of a rare endemic cactus and an assessment of its genetic relationship with a more common congener. Genetica 146(3):329-340 DOI 10.1007/s10709-018-0024-0

Peer] reviewing PDF | (2019:04:37034:3:0:NEW 22 May 2020) 
581

582

583

584

585

586

587

588

589

590

591

592

593

594

595

596

597

598

599

600

601

602

603

604

605

606

607

608

609

610

611

612

613

614

615

616

617

618

619

620

Reichman O J. 1984. Spatial and temporal variation of seed distributions in sonoran desert soils. Journal of Biogeography 11(1):1-11 DOI 10.2307/2844771

Rohlfs R V, Weir B S. 2008. Distributions of hardy-weinberg equilibrium test statistics. Genetics 180(3):1609-1616 DOI 10.1534/genetics.108.088005

Rossum F V, Triest L. 2010. Pollen dispersal in an insect-pollinated wet meadow herb along an urban river. Landscape \& Urban Planning 95(4):201-208 DOI 10.1016/j.landurbplan.2010.01.004

Sakiroglu M, Brummer E C. 2017. Identification of loci controlling forage yield and nutritive value in diploid alfalfa using gbs-gwas. Theoretical \& Applied Genetics 130(2):261-268 DOI 10.1007/s00122-016-2782-3

Shao J W, Chen W L, Peng Y Q, Zhu G P, Zhang X P. 2009. Genetic diversity within and among populations of the endangered and endemic species primula merrilliana in china. Biochemical Systematics \& Ecology 37(6):699-706 DOI 10.1016/j.bse.2009.12.001

Shen W, Li H, Sun M, Jiang J. 2012. Dynamics of aeolian sandy land in the yarlung zangbo river basin of tibet, china from 1975 to 2008. Global Planet Change 86-87:0-44 DOI 10.1016/j.gloplacha.2012.01.012

Shen W S. 1996. Floristic features of sand vegetation in the middle reaches of the yarlung zangbo,xizang (tibet). Acta Phytotaxonomica Sinica.

Singh H, Deshmukh R K, Singh A, Singh A K, Gaikwad K, Sharma T R, Mohapatra T, Singh N K. Highly variable SSR markers suitable for rice genotyping using agarose gels. Molecular Breeding 25(2):359-364 DOI 10.1007/s11032-009-9328-1

Slatkin M. 1987. Gene flow and the geographic structure of natural populations. Science 236(4803):787-792 DOI 10.1126/science.3576198

Sonah H, Deshmukh R K, Sharma A, Singh V P, Gupta D K, Gacche R N, Rana J C, Singh N K, Sharma T R. 2011. Genome-wide distribution and organization of microsatellites in plants: an insight into marker development in Brachypodium. Plos One 6(6): e21298 DOI 10.1371/journal.pone.0021298

Spielman D, Brook B W, Frankham R. 2004. Most species are not driven to extinction before genetic factors impact them. Proceedings of the National Academy of Sciences 101(42):15261-15264 DOI 10.1073/pnas.0403809101

Su G, Yang W, Meng W, Wu Q, Luo Y, Ma X, Zhao S, Xie X, Gou G. 2017. Antiproliferation effects of ethanolic extracts from sophora moorcroftiana seeds on human hepatocarcinoma hepg2 cell line. Natural Product Research 32(13):1-4 DOI 10.1080/14786419.2017.1353503

Tajima F. 1989. Statistical method for testing the neutral mutation hypothesis by dna polymorphism. Genetics 123(3):585-595 DOI 10.0000/PMID2513255

Tel-Zur N, Abbo S, Myslabodski D, Mizrahi Y. 1999. Modified ctab procedure for dna isolation from epiphytic cacti of the genera hylocereus and selenicereus (cactaceae). Plant Molecular Biology Reporter 17(3):249-254 DOI 10.1023/A:1007656315275 
621

622

623

624

625

626

627

628

629

630

631

632

633

634

635

636

637

638

639

640

641

642

643

644

645

646

647

648

649

650

651

652

653

654

655

656

657

658

659

660

Thomson J D, Plowright R C. 1980. Pollen carryover, nectar rewards, and pollinator behavior with special reference to diervilla lonicera. Oecologia 46(1):68-74 DOI $10.2307 / 4216130$

Wang S, Liu Y, Xu Y. 1995. The karyotype analysis of sophora moorcroftiana in tibet, china. Grassland of China.

Ward J A, Bhangoo J, Fernández-Fernández, Felicidad, Moore P, Swanson J D, Viola R, Velasco R, Bassil N, Weber C A, Sargent D J. 2013. Saturated linkage map construction in rubus idaeus using genotyping by sequencing and genome-independent imputation. BMC Genomics 14(1):2-2 DOI 10.1186/1471-2164-14-2

Weir B S, Cockerham C C. 1984. Estimating f-statistics for the analysis of population structure. Evolution 38(6):1358-1370 DOI 10.1111/j.1558-5646.1984.tb05657.x

Whitlock M C, Mccauley D E. 1999. Indirect measures of gene flow and migration: $F_{\mathrm{ST}} \neq$ 1/ $(4 N m+1)$. Heredity 82(2):117-125 DOI 10.1038/sj.hdy.6884960

Wright S. 1951. The genetical structure of populations. Ann. Eugenics 15:323-354.

Wright S. 1965. The interpretation of population structure by f-statistics with special regard to systems of mating. Evolution 19(3):395-420 DOI 10.2307/2406450

Wu B, Zhong G Y, Yue J Q, Yang R T, Li C, Li Y J, Zhong Y, Wang X, Jiang B, Zeng J W, Zhang L, Yan S T, Bei X J, Zhou D G, Wu S B. 2014. Identification of pummelo cultivars by using a panel of 25 selected snps and 12 dna segments. Plos One 9 DOI 10.1371/journal.pone.0094506

Wu Z Y. 1983. Flora Xizangica. Science Press, Beijng, China.

Wu Z Y. 1987. Origin and evolution of flora of Xizang. Flora Xizangica, Science Press, Beijing, China.

Xu Z, Li F, Sun J. 2006. Analysis on dynamic changes and its causes of sandy desertfication in tibet. Central South Forest Inventory \& Planning.

Yang J, Lee S H, Goddard M E, Visscher P M. 2011. Gcta: a tool for genome-wide complex trait analysis. American Journal of Human Genetics 88(1):76-82 DOI 10.1016/j.ajhg.2010.11.011

Yang P. 2013. Atlas of Comprehensive Nature and Desertification of the Tibetan Plateau. Science Press 28-33

Young A, Boyle T, Brown T. 1996. The population genetic consequences of habitat fragmentation for plants. Trends in ecology \& evolution 11(10):413-418 DOI 10.1016/0169-5347(96)10045-8

Zhang F, Hu C, Cheng S, Wang S, Li B, Cao D, Fan H, Pan R, Yang M, Xu Y. 2018. The investigation of the effect and mechanism of sophora moorcroftiana alkaloids in combination with albendazole on echinococcosis in an experimental rats model. Evidence-Based Complementary and Alternative Medicine 2018:1-10 DOI $10.1155 / 2018 / 3523126$

Zhang J, Yan L, Wang L, Zhao D, Zhang T, Song X, Dang Z, Pei X. 2018. Consensus genetic linkage map construction and qtl mapping for plant height-related traits in 
661

662

663

664

665

666

667

668

669

670

671

672

673 linseed flax (linum usitatissimum 1.) Bmc Plant Biology 18(1):160 DOI 10.1186/s12870-018-1366-6

Zhao A, Liu Z, Kang X, Zhou S. 2003. Allozyme variation in sophora moorcroftiana, an endemic species of tibet, china. Chinese Biodiversity 11(2):91-99 DOI 10.1007/BF02948893

Zhao W. 1998. A preliminary study on the arenaceous adaptability of sophora moorcroftiana. Acta Phytoecologica Sinica 22(4).

Zhao W, Zhang Z, Li Q. 2007. Growth and reproduction of Sophora moorcroftiana responding to altitude and sand burial in the middle Tibet. Environmental geology 53(1):11-17 DOI 10.1007/s00254-006-0613-6

Zou X-Y, Li S, Zhang C-L, Dong G-R, Dong Y-X, Yan P. 2002. Desertification and control plan in the tibet autonomous region of china. Journal of Arid Environments 51(2):0-198 DOI 10.1006/jare.2001.0943 
Figure 1

Geographic distribution of sampled S. moorcroftiana populations in the Yarlung Zangbo River basin.

Each population is indicated by a dot on the map. The information of climate reginalization information was obtained from Yang (2013).

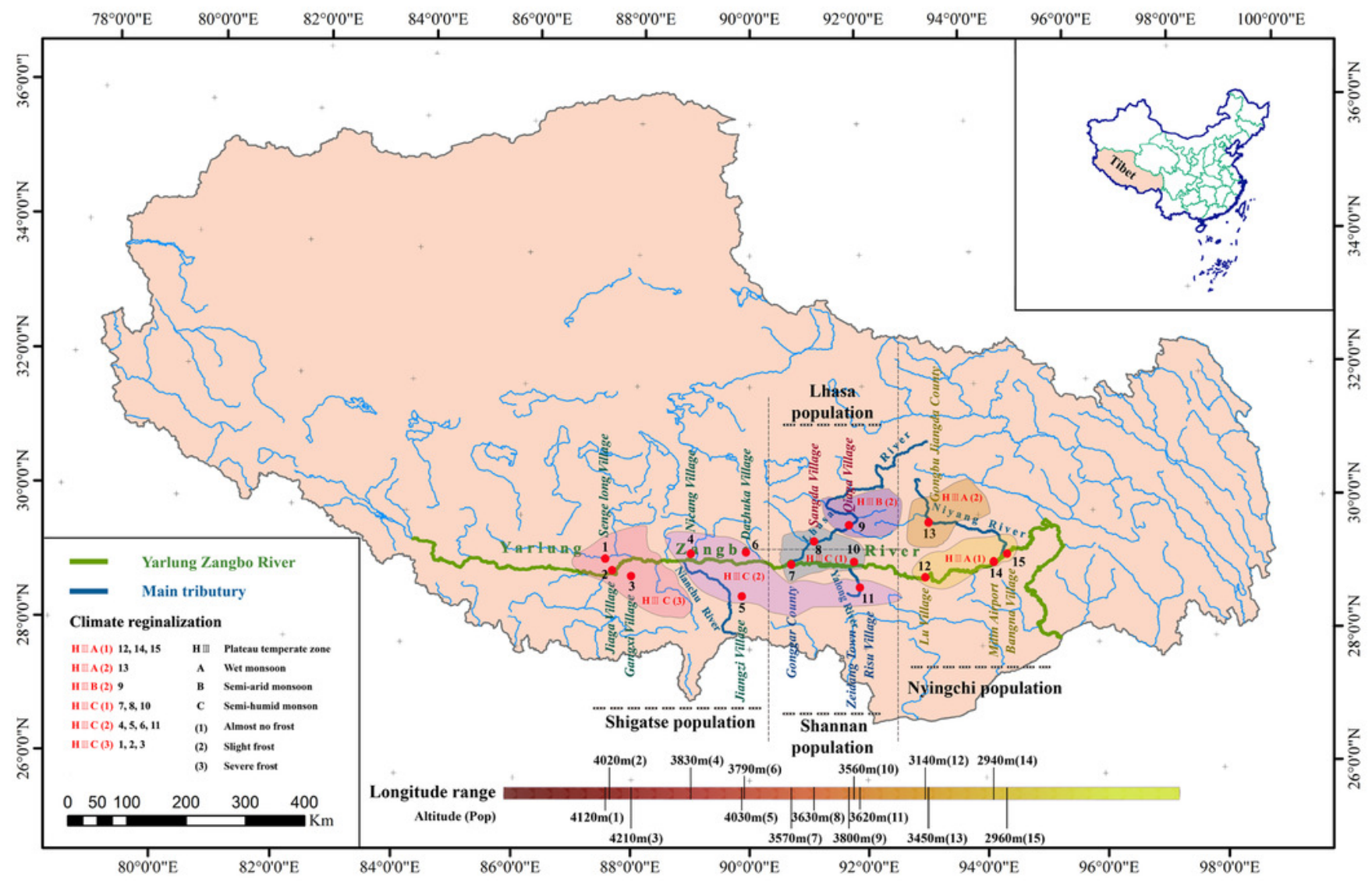




\section{Figure 2}

Neighbor-Joining tree based on SNP data of 225 S. moorcroftiana individuals and 4 S. davidii individuals.

The periphery of the tree includes the population location information and population information, and the inner part indicates the individual number.

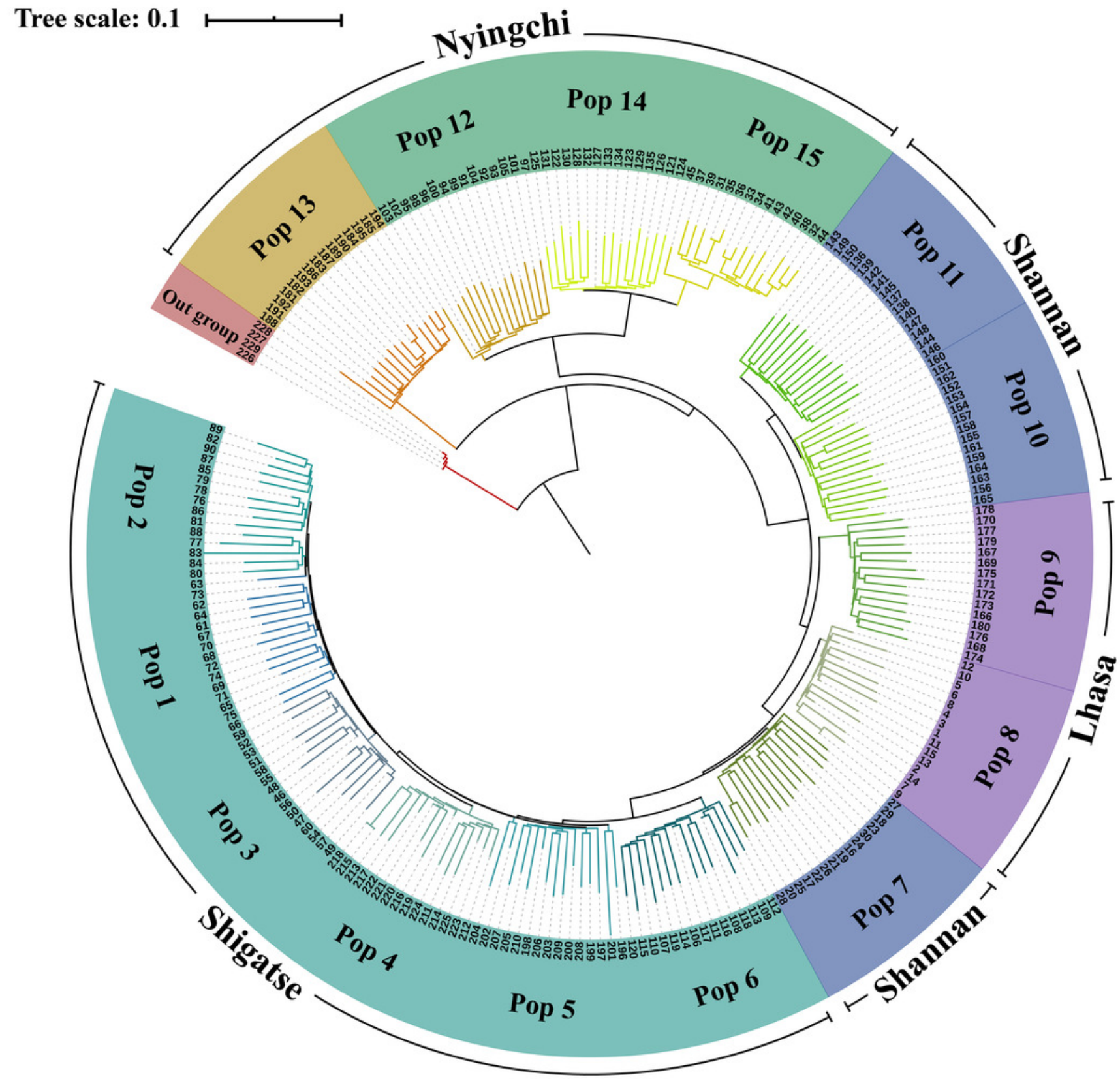


Figure 3

Population genetic structure analysis based on SNP data of 225 S. moorcroftiana individuals ( $K=2$ to 9 ).

(A) The CV error varies among $K$ values. (B) Clustering information for different individuals when $K=2$ to 9 . 
A.

B.
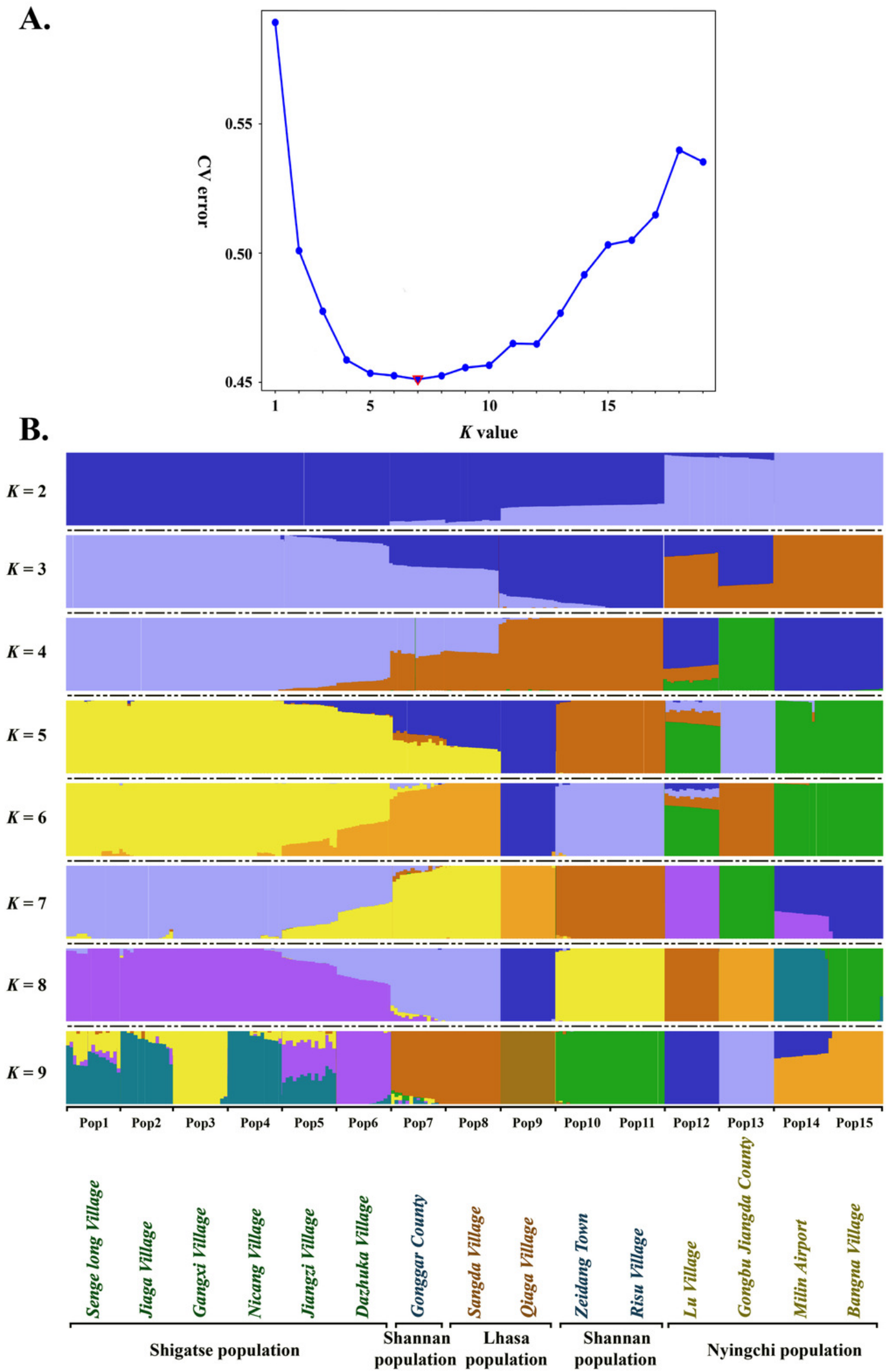
Figure 4

Principal component analysis based on SNP data of 225 S. moorcroftiana individuals and 4 S. davidii individuals.

(A) $P C 1 \& P C 2$. (B) PC1 \& PC3. (C) PCA in 3D. (D) PCA results corresponding to the geographical locations. 


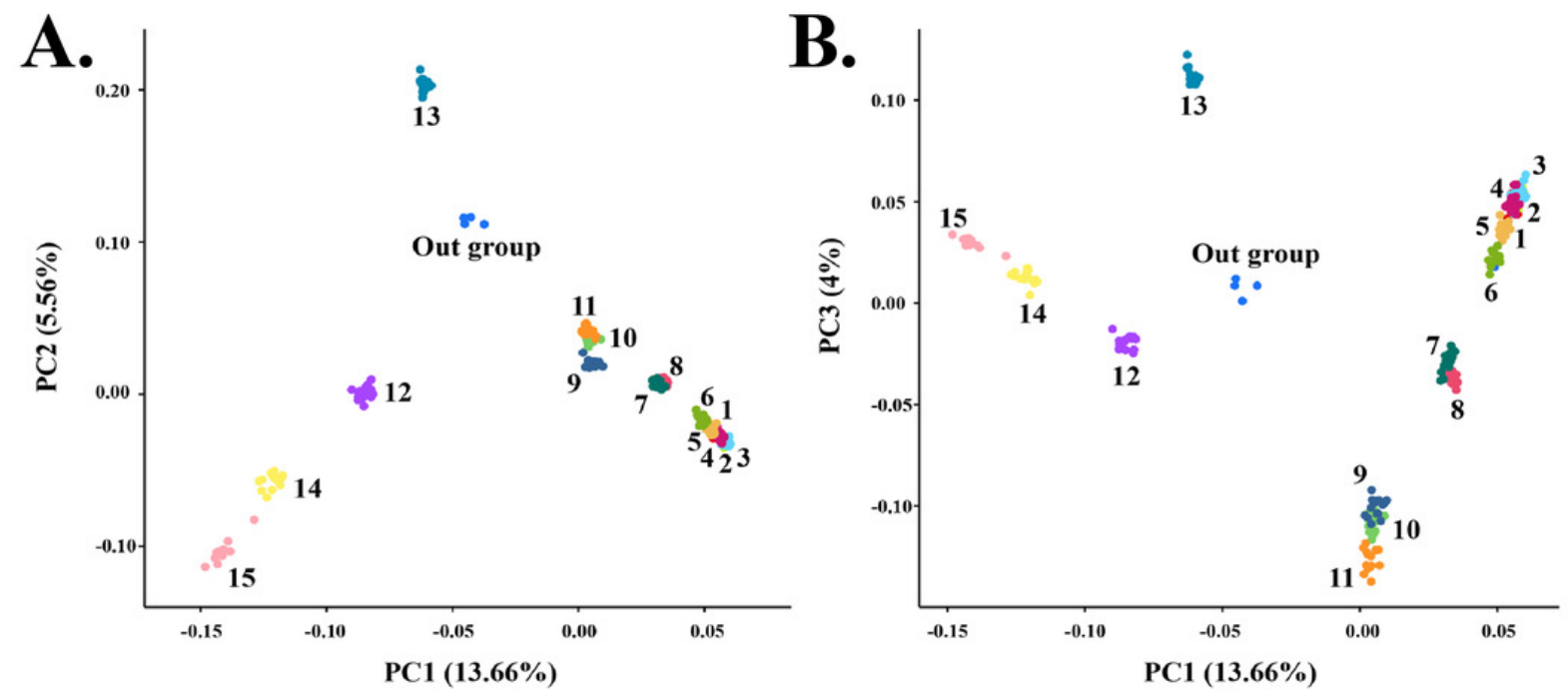

C.

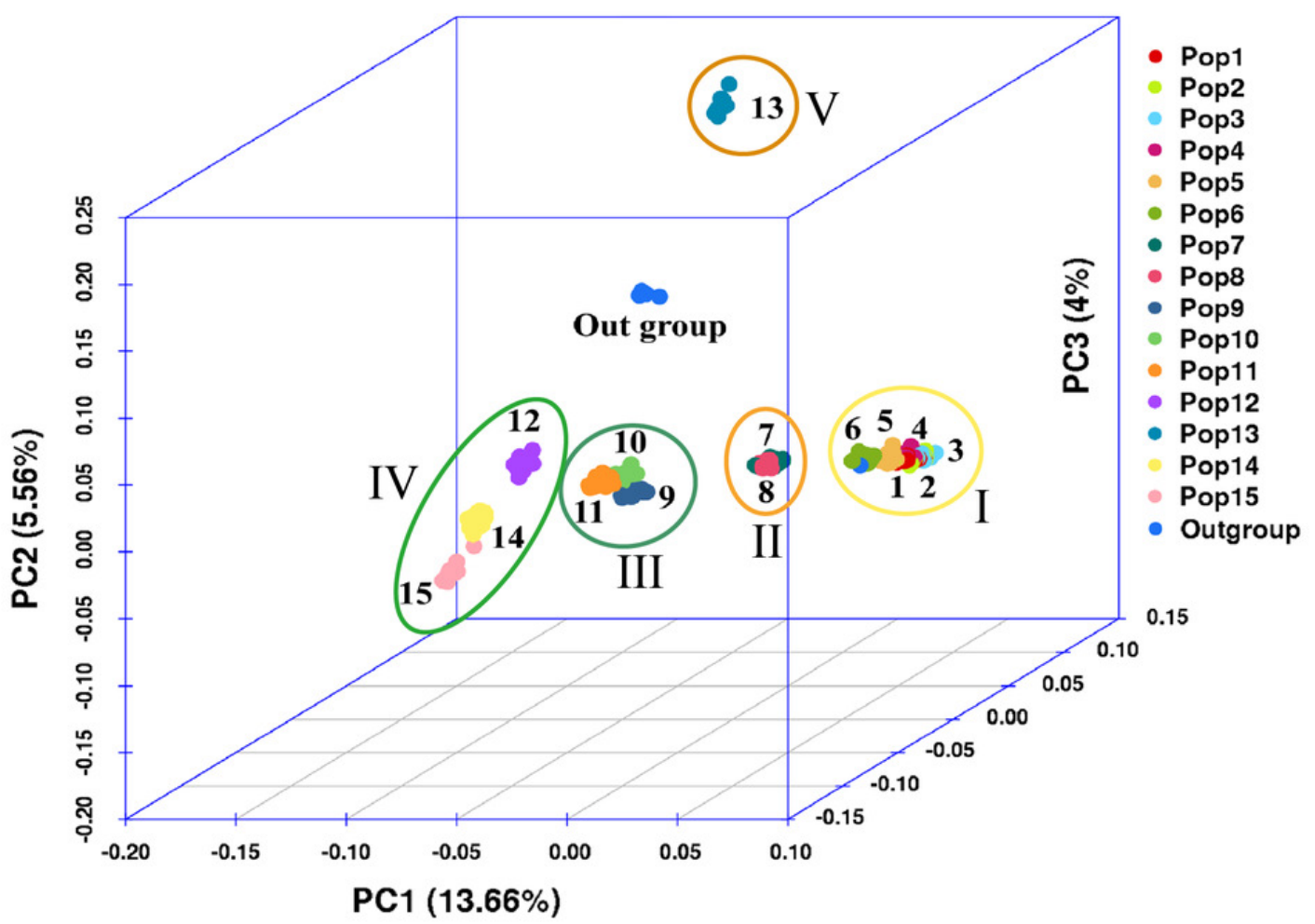

D.

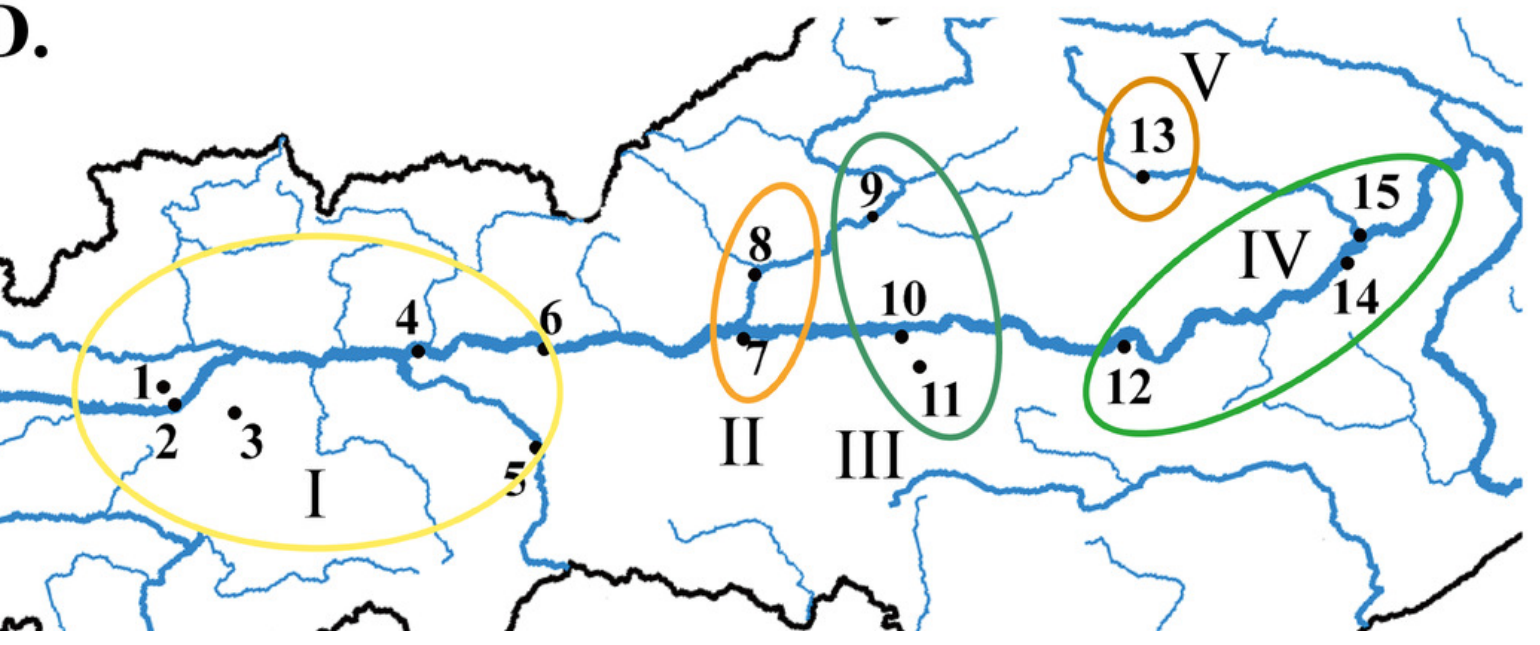

Peer) reviewing PDF | (2019:04:37034:3:0:NEW 22 May 2020) 
Figure 5

Relationship between genetic variation of $15 \mathrm{~S}$. moorcroftiana populations and longitude.

(A) Relationship between PIC and longitude. (B) Relationship between Shanon and longitude.

(C) Relationship between PI and longitude. (D) Relationship between altitude and longitude.
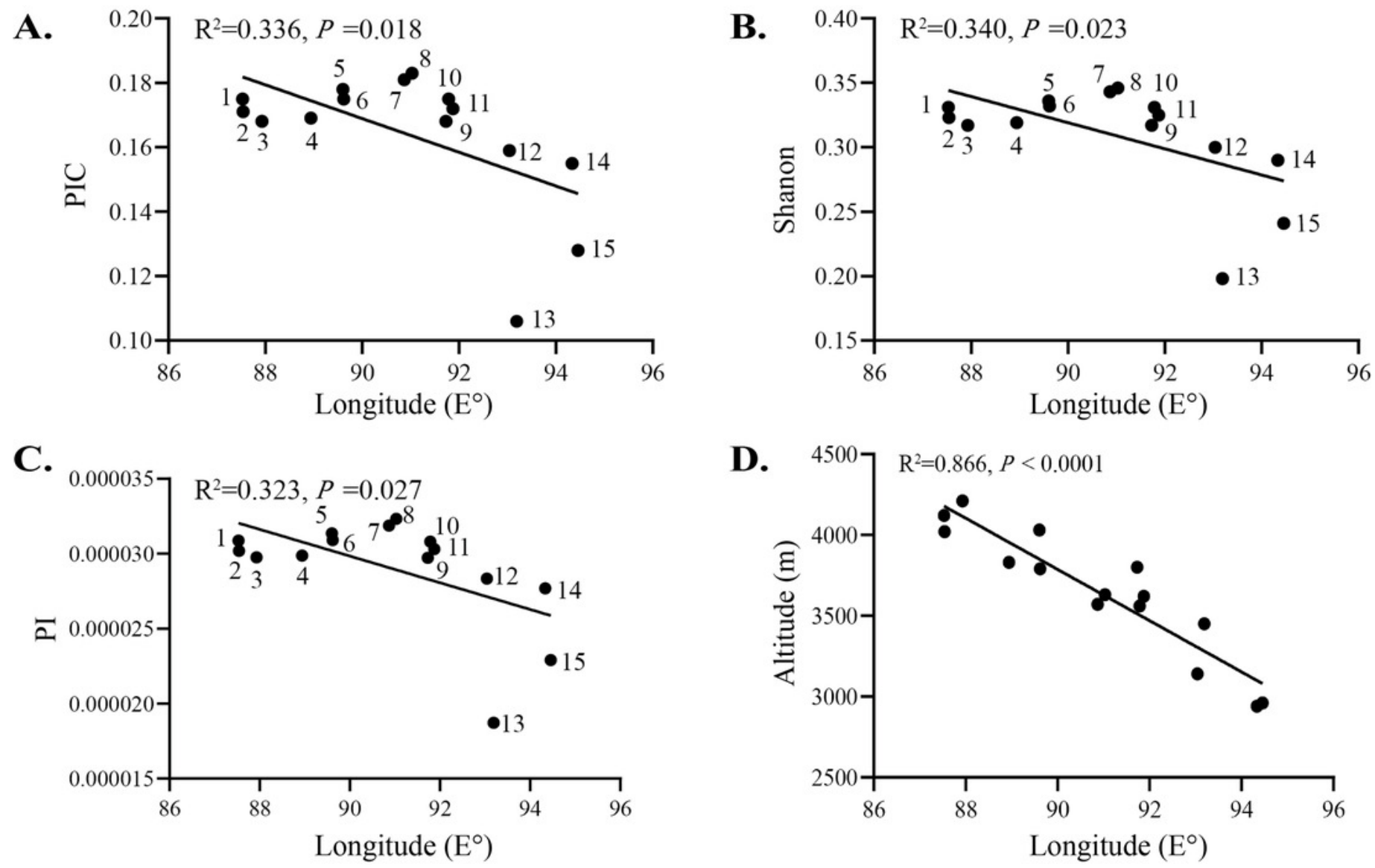


\section{Figure 6}

Wind speed and direction change around the sampling area observed by Lhasa Airport from 1980-2006 (Li et al. 2010).

N: north; NNE: north-northeast; NE: northeast; ENE: east-northeast; E: east; ESE: east-

southeast; SE: southeast; SSE: south-southeast; S: south; SSW: south-southwest; SW:

southwest; WSW: west-southwest; W: west; WNW: west-northwest; NW: northwest; NNW: north-northwest. 


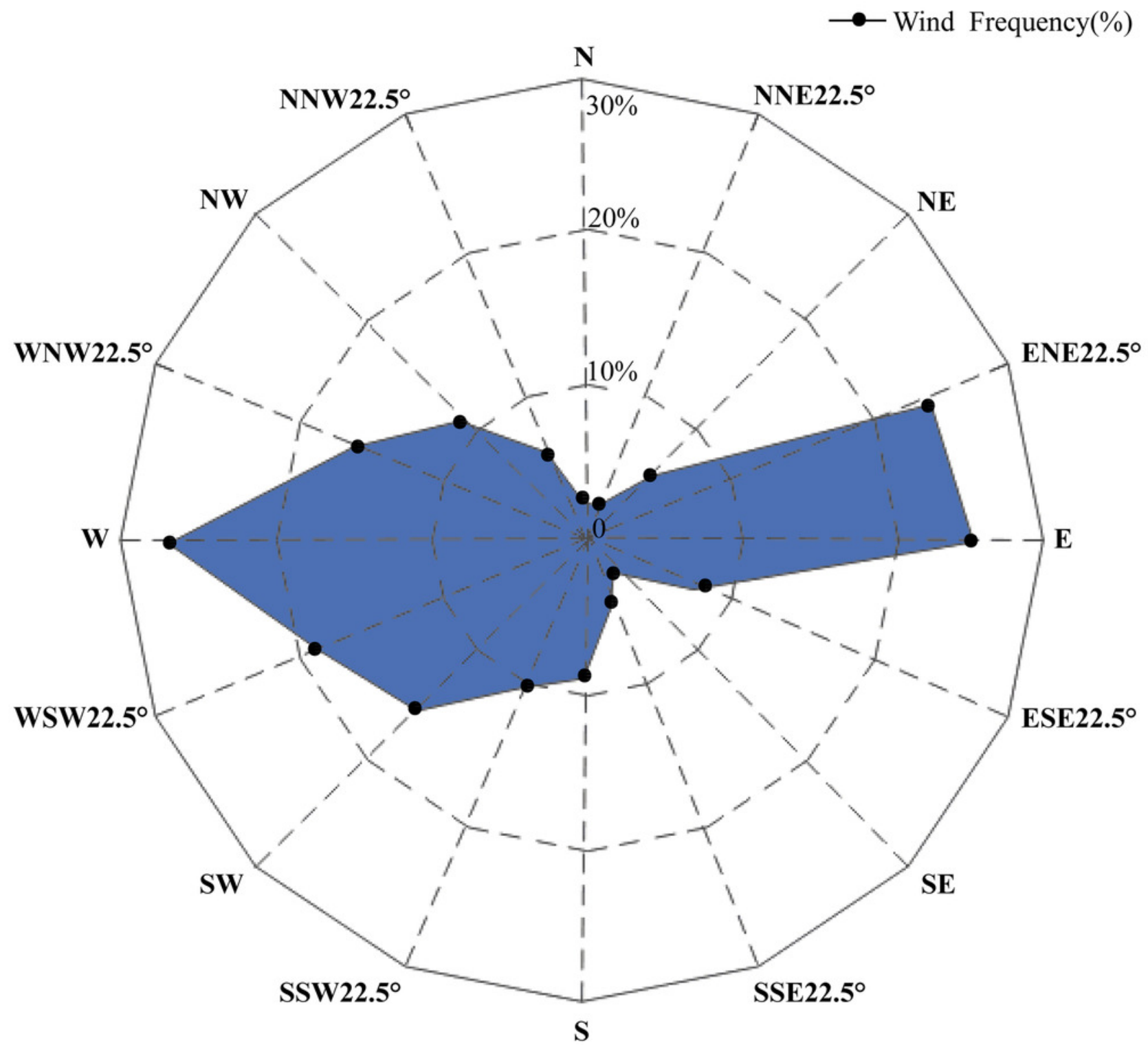




\section{Table $\mathbf{1}$ (on next page)}

Geographic and climate information for the S. moorcroftiana populations in the study.

All the climate information was obtained from Yang (2013). 


\begin{tabular}{|c|c|c|c|c|c|c|c|c|}
\hline $\begin{array}{l}\text { Population } \\
\text { Number }\end{array}$ & $\begin{array}{l}\text { Individual } \\
\text { Number }\end{array}$ & Origin & $\begin{array}{l}\text { Altitude } \\
\text { (m) }\end{array}$ & $\begin{array}{l}\text { Longitude } \\
\qquad\left(\mathrm{E}^{\circ}\right)\end{array}$ & $\begin{array}{l}\text { Latitude } \\
\qquad\left(\mathrm{N}^{\circ}\right)\end{array}$ & $\begin{array}{c}\text { Mean } \\
\text { annual } \\
\text { temperature } \\
\left({ }^{\circ} \mathrm{C}\right)\end{array}$ & $\begin{array}{l}\text { Mean annual } \\
\text { precipitation } \\
(\mathrm{mm})\end{array}$ & $\begin{array}{l}\text { Mean annual } \\
\text { wind velocity } \\
(\mathrm{m} / \mathrm{s})\end{array}$ \\
\hline Pop 1 & $61-75$ & Shigatse, Senge long Village & 4120 & $87^{\circ} 31^{\prime} 49^{\prime \prime}$ & $29^{\circ} 09^{\prime} 24^{\prime \prime}$ & 5 & 400 & $2.6 \sim 3.0$ \\
\hline Pop 2 & $76-90$ & $\begin{array}{c}\text { Shigatse, Chawu Township, } \\
\text { JiagaVillage }\end{array}$ & 4020 & $87^{\circ} 32^{\prime} 21^{\prime \prime}$ & $29^{\circ} 067^{\prime} 57^{\prime \prime}$ & 5 & 400 & $2.6 \sim 3.0$ \\
\hline Pop 3 & $46-60$ & Shigatse, Gangxi Village & 4210 & $87^{\circ} 55^{\prime} 57^{\prime \prime}$ & $29^{\circ} 03^{\prime} 40^{\prime \prime}$ & 5 & 400 & $2.6 \sim 3.0$ \\
\hline Pop 4 & $211-225$ & Shigatse, Nicang Village & 3830 & $88^{\circ} 55^{\prime} 80^{\prime \prime}$ & $29^{\circ} 19^{\prime} 00^{\prime \prime}$ & 5 & 400 & $1.0 \sim 1.4$ \\
\hline Pop 5 & $196-210$ & Shigatse, Near Jiangzi County & 4030 & $89^{\circ} 36^{\prime} 18^{\prime \prime}$ & $28^{\circ} 54^{\prime} 51^{\prime \prime}$ & 5 & 500 & $1.8 \sim 2.2$ \\
\hline Pop 6 & $106-120$ & Shigatse, West of Dazhuka & 3790 & $89^{\circ} 37^{\prime} 17^{\prime \prime}$ & $29^{\circ} 20^{\prime} 28^{\prime \prime}$ & 5 & 400 & $1.4 \sim 1.8$ \\
\hline Pop 7 & $16-30$ & Shannan, Gonggar County & 3570 & $90^{\circ} 52^{\prime} 15^{\prime \prime}$ & $29^{\circ} 17^{\prime} 38^{\prime \prime}$ & 7 & 400 & $1.8 \sim 2.2$ \\
\hline Pop 8 & $1-15$ & Lhasa, Sangda Village & 3630 & $91^{\circ} 01^{\prime} 49^{\prime \prime}$ & $29^{\circ} 33^{\prime} 26^{\prime \prime}$ & 5 & 500 & $1.8 \sim 2.2$ \\
\hline Pop 9 & $166-180$ & $\begin{array}{c}\text { Lhasa, Mozhu, Gongka Town, } \\
\text { Qiaga Village }\end{array}$ & 3800 & $91^{\circ} 43^{\prime} 41^{\prime \prime}$ & $29^{\circ} 50^{\prime} 10^{\prime \prime}$ & 3 & 500 & $1.8 \sim 2.2$ \\
\hline Pop 10 & $151-165$ & Shannan, North of Zeidang Town & 3560 & $91^{\circ} 47^{\prime} 09^{\prime \prime}$ & $29^{\circ} 14^{\prime} 42^{\prime \prime}$ & 7 & 400 & $2.2 \sim 2.6$ \\
\hline Pop 11 & $136-150$ & $\begin{array}{c}\text { Shannan, Naidong County, Risu } \\
\text { Village }\end{array}$ & 3620 & $91^{\circ} 52^{\prime} 29^{\prime \prime}$ & $29^{\circ} 00^{\prime} 33^{\prime \prime}$ & 7 & 400 & $2.2 \sim 2.6$ \\
\hline Pop 12 & $91-105$ & $\begin{array}{c}\text { Nyingchi, west of Lang County, Lu } \\
\text { Village }\end{array}$ & 3140 & $93^{\circ} 02^{\prime} 31^{\prime \prime}$ & $29^{\circ} 02^{\prime} 57^{\prime \prime}$ & 7 & 500 & $1.8 \sim 2.2$ \\
\hline Pop13 & $181-195$ & Nyingchi, Gongbu Jiangda County & 3450 & $93^{\circ} 11^{\prime} 30^{\prime \prime}$ & $29^{\circ} 53^{\prime} 50^{\prime \prime}$ & 3 & 500 & $1.8 \sim 2.2$ \\
\hline Pop 14 & $121-135$ & $\begin{array}{c}\text { Nyingchi, Near Milin Airport, } \\
\text { Hongwei Forest }\end{array}$ & 2940 & $94^{\circ} 20^{\prime} 10^{\prime \prime}$ & $29^{\circ} 19^{\prime} 06^{\prime \prime}$ & 7 & 700 & $1.8 \sim 2.2$ \\
\hline Pop 15 & $31-45$ & Nyingchi, Bangna Village & 2960 & $94^{\circ} 27^{\prime} 36^{\prime \prime}$ & $29^{\circ} 27^{\prime} 27^{\prime \prime}$ & 7 & 800 & $1.8 \sim 2.2$ \\
\hline
\end{tabular}




\section{Table 2 (on next page)}

Estimates of genetic variability of 15 S. moorcroftiana populations.

PIC: polymorphism information content; Shannon: Shannon-Wiener index; PI: Nucleotide diversity; Ho: observed heterozygosity; He: expected heterozygosity. Species-level estimates were computed treating the 15 populations as a whole. 


\begin{tabular}{|c|c|c|c|c|c|c|}
\hline Population & PIC & Shanon & PI & Tajimas'D & Ho & $\mathrm{He}$ \\
\hline Pop 1 & 0.175 & 0.331 & 0.00003088 & 0.829 & 0.2892 & 0.3018 \\
\hline Pop 2 & 0.171 & 0.323 & 0.00003019 & 0.838 & 0.2724 & 0.3023 \\
\hline Pop 3 & 0.168 & 0.317 & 0.00002975 & 0.962 & 0.3223 & 0.3098 \\
\hline Pop 4 & 0.169 & 0.319 & 0.00002988 & 0.884 & 0.3193 & 0.3048 \\
\hline Pop 5 & 0.178 & 0.336 & 0.00003135 & 0.787 & 0.2768 & 0.3014 \\
\hline Pop 6 & 0.175 & 0.332 & 0.00003091 & 0.755 & 0.2878 & 0.2971 \\
\hline Pop 7 & 0.181 & 0.343 & 0.00003188 & 0.734 & 0.2728 & 0.2956 \\
\hline Pop 8 & 0.183 & 0.346 & 0.00003233 & 0.877 & 0.3249 & 0.3048 \\
\hline Pop 9 & 0.168 & 0.317 & 0.00002972 & 0.900 & 0.2821 & 0.3060 \\
\hline Pop 10 & 0.175 & 0.331 & 0.00003080 & 0.712 & 0.2709 & 0.2965 \\
\hline Pop 11 & 0.172 & 0.325 & 0.00003031 & 0.831 & 0.2701 & 0.3019 \\
\hline Pop 12 & 0.159 & 0.300 & 0.00002834 & 1.046 & 0.2931 & 0.3170 \\
\hline Pop 13 & 0.106 & 0.198 & 0.00001873 & 1.296 & 0.2933 & 0.3364 \\
\hline Pop 14 & 0.155 & 0.290 & 0.00002769 & 1.411 & 0.3147 & 0.3382 \\
\hline Pop 15 & 0.128 & 0.241 & 0.00002291 & 1.279 & 0.3168 & 0.3296 \\
\hline $\begin{array}{c}\text { Mean (at population } \\
\text { level) }\end{array}$ & 0.164 & 0.310 & 0.00002904 & 0.943 & 0.2938 & 0.3095 \\
\hline $\begin{array}{l}\text { Species-level } \\
\text { values }\end{array}$ & & & & & 0.1919 & 0.2661 \\
\hline
\end{tabular}

1 


\section{Table 3(on next page)}

Pairwise comparison of genetic differentiation $\left(F_{\mathrm{ST}}\right)$ among 15 S. moorcroftiana populations. 


\begin{tabular}{|c|c|c|c|c|c|c|c|c|c|c|c|c|c|c|}
\hline & Pop1 & Pop2 & Pop3 & Pop4 & Pop5 & Pop6 & Pop7 & Pop8 & Pop9 & Pop10 & Pop11 & Pop12 & Pop13 & Pop14 \\
\hline Pop2 & 0.021 & & & & & & & & & & & & & \\
\hline Pop3 & 0.041 & 0.062 & & & & & & & & & & & & \\
\hline Pop4 & 0.048 & 0.050 & 0.071 & & & & & & & & & & & \\
\hline Pop5 & 0.029 & 0.046 & 0.059 & 0.060 & & & & & & & & & & \\
\hline Pop6 & 0.077 & 0.092 & 0.100 & 0.101 & 0.052 & & & & & & & & & \\
\hline Pop7 & 0.092 & 0.105 & 0.116 & 0.111 & 0.084 & 0.093 & & & & & & & & \\
\hline Pop8 & 0.104 & 0.118 & 0.132 & 0.124 & 0.095 & 0.104 & 0.050 & & & & & & & \\
\hline Pop9 & 0.187 & 0.202 & 0.211 & 0.203 & 0.176 & 0.181 & 0.139 & 0.132 & & & & & & \\
\hline Pop10 & 0.164 & 0.172 & 0.185 & 0.175 & 0.150 & 0.161 & 0.112 & 0.128 & 0.152 & & & & & \\
\hline Pop11 & 0.185 & 0.193 & 0.205 & 0.198 & 0.172 & 0.183 & 0.134 & 0.150 & 0.174 & 0.049 & & & & \\
\hline Pop12 & 0.290 & 0.299 & 0.308 & 0.301 & 0.278 & 0.287 & 0.247 & 0.257 & 0.250 & 0.225 & 0.241 & & & \\
\hline Pop13 & 0.387 & 0.395 & 0.404 & 0.396 & 0.375 & 0.383 & 0.344 & 0.352 & 0.372 & 0.334 & 0.350 & 0.336 & & \\
\hline Pop14 & 0.334 & 0.343 & 0.351 & 0.345 & 0.324 & 0.331 & 0.294 & 0.303 & 0.303 & 0.277 & 0.291 & 0.160 & 0.377 & \\
\hline Pop15 & 0.401 & 0.410 & 0.418 & 0.411 & 0.392 & 0.398 & 0.366 & 0.372 & 0.373 & 0.352 & 0.368 & 0.250 & 0.458 & 0.151 \\
\hline
\end{tabular}

1 
Table 4 (on next page)

Gene flow (Nm) among $15 \mathrm{~S}$. moorcroftiana populations. 


\begin{tabular}{|c|c|c|c|c|c|c|c|c|c|c|c|c|c|c|}
\hline & Pop1 & Pop2 & Pop3 & Pop4 & Pop5 & Pop6 & Pop7 & Pop8 & Pop9 & Pop10 & Pop11 & Pop12 & Pop13 & Pop14 \\
\hline Pop2 & 11.601 & & & & & & & & & & & & & \\
\hline Pop3 & 5.807 & 3.773 & & & & & & & & & & & & \\
\hline Pop4 & 4.951 & 4.709 & 3.253 & & & & & & & & & & & \\
\hline Pop5 & 8.228 & 5.226 & 4.003 & 3.943 & & & & & & & & & & \\
\hline Pop6 & 3.013 & 2.458 & 2.260 & 2.231 & 4.568 & & & & & & & & & \\
\hline Pop7 & 2.460 & 2.133 & 1.900 & 1.994 & 2.741 & 2.426 & & & & & & & & \\
\hline Pop8 & 2.143 & 1.862 & 1.640 & 1.772 & 2.393 & 2.164 & 4.750 & & & & & & & \\
\hline Pop9 & 1.085 & 0.988 & 0.935 & 0.980 & 1.171 & 1.129 & 1.544 & 1.639 & & & & & & \\
\hline Pop10 & 1.278 & 1.203 & 1.102 & 1.179 & 1.417 & 1.299 & 1.981 & 1.708 & 1.399 & & & & & \\
\hline Pop11 & 1.101 & 1.047 & 0.970 & 1.010 & 1.199 & 1.117 & 1.614 & 1.413 & 1.188 & 4.826 & & & & \\
\hline Pop12 & 0.612 & 0.586 & 0.560 & 0.582 & 0.651 & 0.620 & 0.761 & 0.724 & 0.752 & 0.861 & 0.785 & & & \\
\hline Pop13 & 0.395 & 0.382 & 0.368 & 0.381 & 0.417 & 0.403 & 0.477 & 0.461 & 0.422 & 0.498 & 0.464 & 0.494 & & \\
\hline Pop14 & 0.498 & 0.478 & 0.463 & 0.474 & 0.522 & 0.505 & 0.600 & 0.576 & 0.576 & 0.653 & 0.611 & 1.314 & 0.414 & \\
\hline Pop15 & 0.373 & 0.360 & 0.348 & 0.358 & 0.388 & 0.379 & 0.433 & 0.421 & 0.421 & 0.460 & 0.430 & 0.751 & 0.296 & 1.410 \\
\hline
\end{tabular}

1 
Table 5 (on next page)

Estimates of genetic variability of $4 \mathrm{~S}$. moorcroftiana subgroups. 


\begin{tabular}{ccccccc}
\hline Population & PIC & Shanon & PI & Tajimas'D & $H \mathrm{o}$ & $H \mathrm{e}$ \\
\hline subgroup I & 0.189 & 0.359 & 0.00003204 & 1.857 & 0.2453 & 0.2745 \\
subgroup II & 0.192 & 0.363 & 0.00003293 & 1.148 & 0.2699 & 0.2834 \\
subgroup III & 0.195 & 0.370 & 0.00003314 & 1.253 & 0.2186 & 0.2704 \\
subgroup IV & 0.174 & 0.329 & 0.00003025 & 1.898 & 0.2438 & 0.3071 \\
\hline
\end{tabular}

1 
Table 6(on next page)

Gene flow (Nm) among 4 S. moorcroftiana subgroups. 


\begin{tabular}{cccc}
\hline & Subgroup I & Subgroup II & Subgroup III \\
\hline Subgroup II & 3.271 & & \\
Subgroup III & 1.803 & 2.894 & \\
Subgroup IV & 0.633 & 0.744 & 0.918 \\
\hline
\end{tabular}

1 